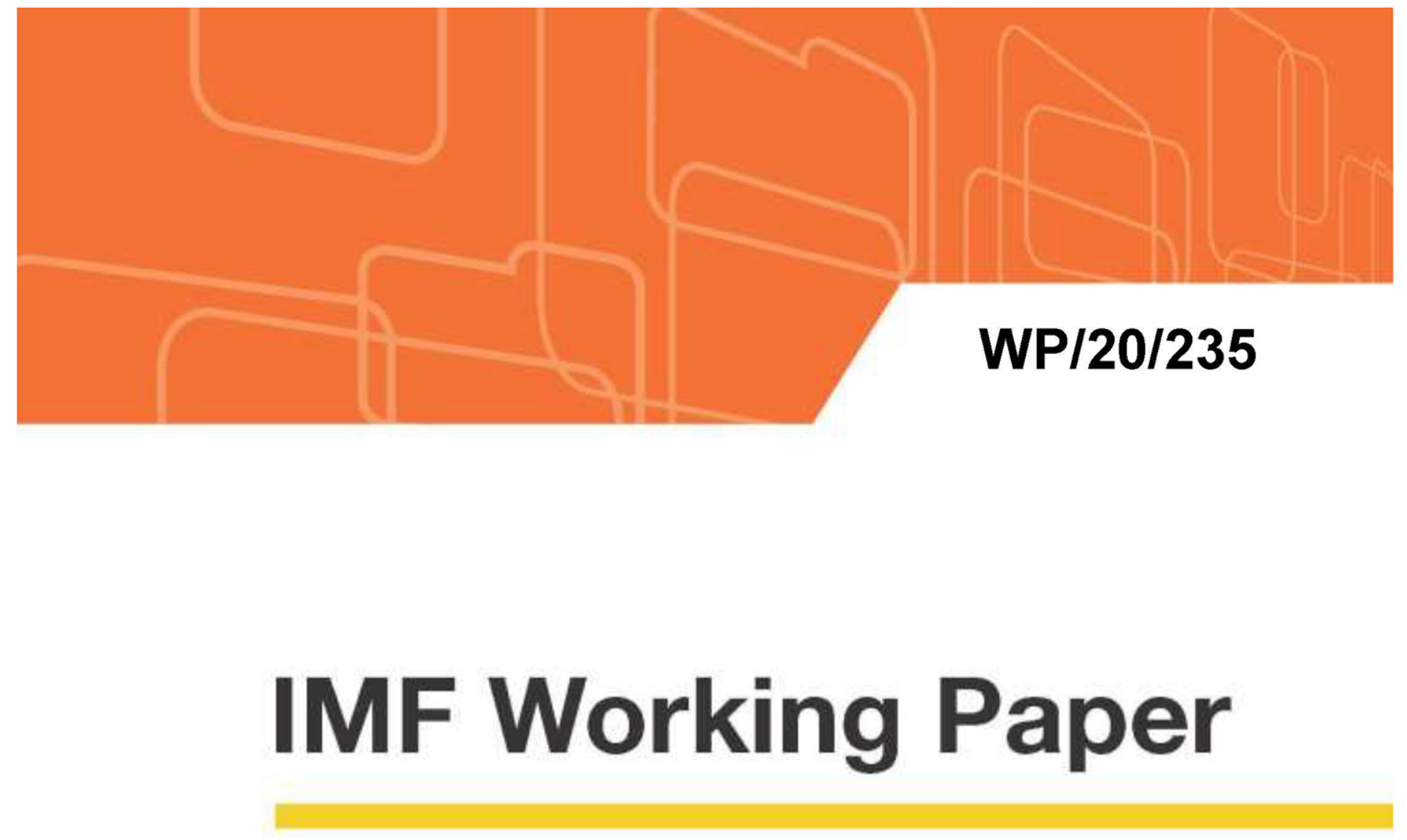

\title{
Climate Mitigation Policy in Denmark: A Prototype for Other Countries
}

by Nicoletta Batini, lan Parry, and Philippe Wingender

IMF Working Papers describe research in progress by the author(s) and are published to elicit comments and to encourage debate. The views expressed in IMF Working Papers are those of the author(s) and do not necessarily represent the views of the IMF, its Executive Board, the Independent Evaluation Office or IMF management. 


\section{WP/20/235}

\section{IMF Working Paper}

\section{Climate Mitigation Policy in Denmark: A Prototype for Other Countries}

by Nicoletta Batini, Ian Parry, and Philippe Wingender

IMF Working Papers describe research in progress by the author(s) and are published to elicit comments and to encourage debate. The views expressed in IMF Working Papers are those of the author(s) and do not necessarily represent the views of the IMF, its Executive Board, the Independent Evaluation Office or IMF management.
I N T E P I I
N A T I
N A L
$M O N E T A R Y$ 


\title{
IMF Working Paper
}

European Department

\section{Climate Mitigation Policy in Denmark: A Prototype for Other Countries}

\author{
Prepared by Nicoletta Batini, Ian Parry, and Philippe Wingender ${ }^{1}$
}

Authorized for distribution by Miguel Segoviano

November 2020

\section{IMF Working Papers describe research in progress by the author(s) and are} published to elicit comments and to encourage debate. The views expressed in IMF Working Papers are those of the author(s) and do not necessarily represent the views of the IMF, its Executive Board, the Independent Evaluation Office or IMF management.

\begin{abstract}
Denmark has a highly ambitious goal of reducing greenhouse gas emissions 70 percent below 1990 levels by 2030. While there is general agreement that carbon pricing should be the centerpiece of Denmark's mitigation strategy, pricing needs to be effective, address equity and leakage concerns, and be reinforced by additional measures at the sectoral level. The strategy Denmark develops can be a good prototype for others to follow. This paper discusses mechanisms to scale up domestic carbon pricing, compensate households, and possibly combine pricing with a border carbon adjustment. It also recommends the use of revenue-neutral feebate schemes to strengthen mitigation incentives, particularly for transportation and agriculture, fisheries and forestry, though these schemes could also be applied more widely.
\end{abstract}

JEL Classification Numbers: Q48, Q54, Q58, H23

Keywords: Climate change, Denmark climate mitigation, carbon pricing, feebate, revenue recycling, border carbon adjustment, transportation, agriculture.

Author's E-Mail Addresses: nbatini@,imf.org; iparry@,imf.org; pwingender@,imf.org

\footnotetext{
${ }^{1}$ We are grateful to Juan Carlos Benitez and Khamal Clayton for contributions to the paper and for very helpful comments and suggestions from Miguel Segoviano, Peter Birch Sørensen, Ulla Blatt Bendtsen, Ralph Chami, Cory Hillier, Signe Krogstrup, Lars Haagen Pedersen, Eva Smidt, Vimal Thakoor, several reviewers from various IMF departments as well as colleagues from the Danish Ministry of Finance, Danmarks Nationalbank, Danish Economic Councils, Ministry of Taxation, Danish Council on Climate Change, Ministry of Climate, Energy and Utilities and Ministry of Industry, Business, and Financial Affairs. We also wish to thank Nicholas Werquin for helpful discussions on the generalized compensation approach and for sharing his code. All errors remain our own.
} 


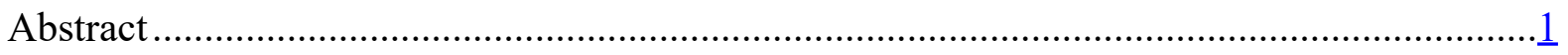

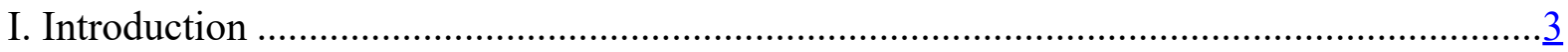

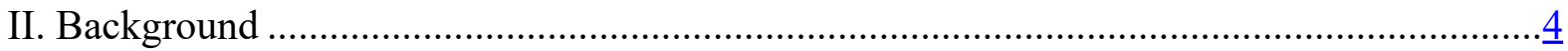

III. Advantages and Limitations of the Existing Policy Framework ..................................11

IV. A Comprehensive Package to Enhance Effectiveness................................................14

A. Reinforcing Carbon Pricing with Feebates ................................................. 14

B. Promoting Equitable Pricing Reform ..................................................... $\frac{19}{25}$

C. Domestic Mechanisms for Addressing Competitiveness and Leakage .................. 25

V. Mitigation Policies for Agriculture, Fisheries and Forestry …..................................... $\underline{30}$

VI. Summary of Policy Recommendations ...........................................................

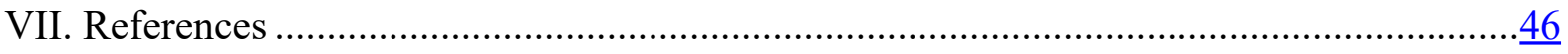

Annex I. Household Incidence of a Carbon Tax..........................................................54

Annex II. Burden of Carbon Mitigation Policies on EITE Industries ................................ 57

Tables

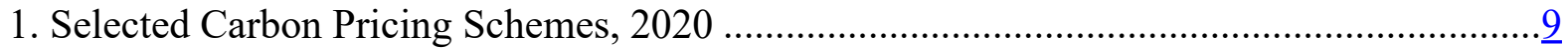

2. Effect of Feebates on Vehicle Prices ..........................................................................17

3. Key Design Issues for BCAs: A Summary ............................................................29

Figures

1. Global Fossil Fuel $\mathrm{CO}_{2}$ Emissions........................................................................

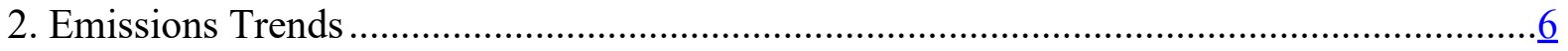

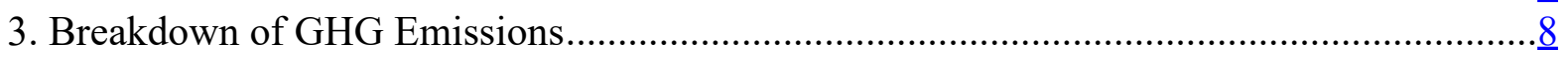

4. Current Prices, Supply, and non-Carbon Environmental Costs, 2015 ......................... 10

5. Reduction in Fossil Fuel $\mathrm{CO}_{2}$ from Emission Targets and Carbon Pricing in 2030 ...........14

6. Energy Price Impacts of Carbon Price, 2030 ...............................................................20

7. Household Energy Consumption, by source...........................................................20

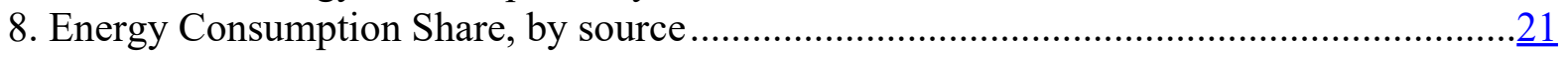

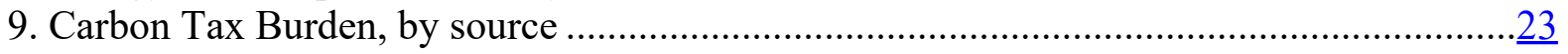

10. Marginal Tax Rate Schedules for Labor Income ..................................................24

11. Changes in Marginal Tax Rates ..............................................................................24

12. Incidence of Carbon Tax and Reform Options ..................................................... $\frac{25}{26}$

13. Carbon Leakage Rate of National Policies ........................................................... $\frac{26}{36}$

14. Total Estimated GHG Emissions in Denmark by Type of Animal (2018) .................... $\underline{36}$

15. Avoidable Mortality (Preventable and Treatable) and Health Expenditure .....................39

16. Total Denmark's Great Whales Catches $(2000-2019)$........................................

\section{Box 1}

1. Sources of Agricultural GHG Emissions in Denmark 


\section{INTRODUCTION}

Denmark has substantially reduced greenhouse gas (GHG) emissions since the mid1990 s and has an ambitious national level commitment to reduce emissions 70 percent by 2030 relative to 1990 levels and to reach net-zero GHG emissions by 2050 at the latest. ${ }^{2}$ Bold policies are needed to complement current policies to achieve this goal. The Danish Council on Climate Change has recommended a carbon price rising to \$200-250 per ton by 2030 as the centerpiece of these efforts. It is difficult, however, to forecast the impact of this steep increase in carbon taxation and to gauge its acceptability. This paper therefore focuses on a package of carbon pricing and other fiscal mitigation instruments that is effective, addresses equity and leakage concerns, and is supported by investments (e.g., in offshore wind). Its outcome is likely also more certain given that measures are spread more evenly across the economy and they thus require less price/quantity adjustments to reach emissions objectives.

Carbon pricing can be strengthened by applying a domestic carbon surcharge to emissions covered by the EU Emissions Trading System (ETS) to meet an escalating target price for these emissions and setting the domestic carbon tax (for other emissions sources) equal to this price. For illustration, a carbon price of $\$ 100$ per ton of $\mathrm{CO}_{2}$ in 2030 imposes a manageable burden on the average household of 1.8 percent of consumption. And this burden could be largely offset for all household income groups by using carbon pricing revenues to finance a 1 percentage point reduction in personal income tax rates, while approximately neutralizing the adverse employment effects of higher energy prices.

\section{A border carbon adjustment (BCA) might be warranted in Denmark to address domestic competitiveness and leakage concerns even though this instrument might ultimately be implemented at the EU level. A Danish BCA - a charge on imports that equalizes the price of embodied carbon regardless of their origin - could be implemented more rapidly and would be a valuable prototype for an EU BCA. And some level of BCA might be retained at the Danish level, given the higher level of ambition in Denmark's national pledge. The main issues would be: (i) whether to limit the BCA to energy-intensive trade-exposed (EITE) sectors or adopt comprehensive taxation of all embodied carbon in Danish consumption; and (ii) whether there would be legal constraints on either approach, including applying the BCA to products from EU countries.}

\section{Additional mitigation instruments, that do not impose first-order tax burdens on households and firms, will be needed to reinforce carbon pricing at the sectoral level, especially where emissions have relatively low price-responsiveness. This paper recommends feebates (rather than more traditional regulations) to reinforce mitigation incentives, most importantly in the transport and agricultural sectors. Feebates apply a revenue-neutral, sliding scale of fees on products or activities with above average emission rates and a sliding scale of rebates on products or activities with below average emission}

\footnotetext{
${ }^{2}$ These emissions targets are in line with the goal of containing global warming to $1.5^{\circ} \mathrm{C}$.
} 
rates. Feebates: (i) provide a more flexible and cost-effective approach than regulations; (ii) can provide very powerful mitigation incentives; (iii) do not impose new tax burdens on the average household or firms; (iv) avoid fiscal burdens for the government; and (v) for the most part can build off existing administrative capacity.

\section{In the transportation sector, feebates can also help to maintain revenues from} registration taxes (currently about 1 percent of GDP). Maintaining tax exemptions for electric vehicles (EVs) will progressively erode the base of the registration tax, whereas under a feebate the relative price of vehicles can be set independently to phase out internal combustion engine (ICE) vehicles and registration taxes can be applied to ICEs and EVs alike to meet fiscal requirements. While transitioning away from ICE vehicles, the Danish government might also consider phasing in kilometer $(\mathrm{km})$ based vehicle charging systems to prevent progressive erosion in fuel tax revenues (about 1 percent of GDP) and effectively reduce road traffic congestion (which currently imposes a large economic cost).

\section{In the agricultural sector, Denmark has a long tradition of collecting farm level data} that could be used to implement a proxy price on emissions from livestock and crop operations. A feebate approach, charging farmers for the difference between their $\mathrm{CO}_{2}$ equivalent emissions per hectare and the industry average per hectare, may be more acceptable than a tax on (estimated) emissions. The latter imposes a new tax burden on all farmers and poses greater risks of emissions leakage. At the consumer level, mitigation incentives could be strengthened by fiscal schemes that raise the relative price of beef, pork and dairy products relative to plant-based food, promising significant health benefits from improved nutrition. Lowering consumption of these products would also help contain the risk of emission leakage cause by differences in international taxation of high-externality foods. Structural reforms to foster a transition toward sustainable agriculture, fishery and forestry activities like regenerative faming on land and at sea, and eco-tourism, can reinforce and accelerate the impact of proposed changes in tax and subsidy policies.

The paper is organized as follows. The next section provides background on emissions trends and policies in Denmark. Section III discusses advantages and limitations of current mitigation policies. Section IV analyses a comprehensive package of pricing and sectoral based mitigation instruments for Denmark. Section V discusses fiscal measures for mitigating agricultural emissions. A final section summarizes the main policy recommendations.

\section{BACKGROUND}

The public health and economic crisis precipitated by the COVID-19 pandemic have not affected the urgent need for clean energy transitions. Global fossil fuel $\mathrm{CO}_{2}$ and other GHGs need to fall rapidly_-by about 25 percent below 2018 levels by 2030 to contain future 
warming to $2^{\circ} \mathrm{C}$, or 50 percent below for the $1.5^{\circ} \mathrm{C}$ target and continue to decline thereafter. ${ }^{3}$ Global $\mathrm{CO}_{2}$ emissions in 2020 are projected to be about 8 percent lower than in 2019, due to both lower GDP and structural shifts (e.g., more remote working). However, emissions are projected to start rising again from 2021 as economies recover from the crisis and structural shifts are partially reversed. Latest projections suggest that with current policies global

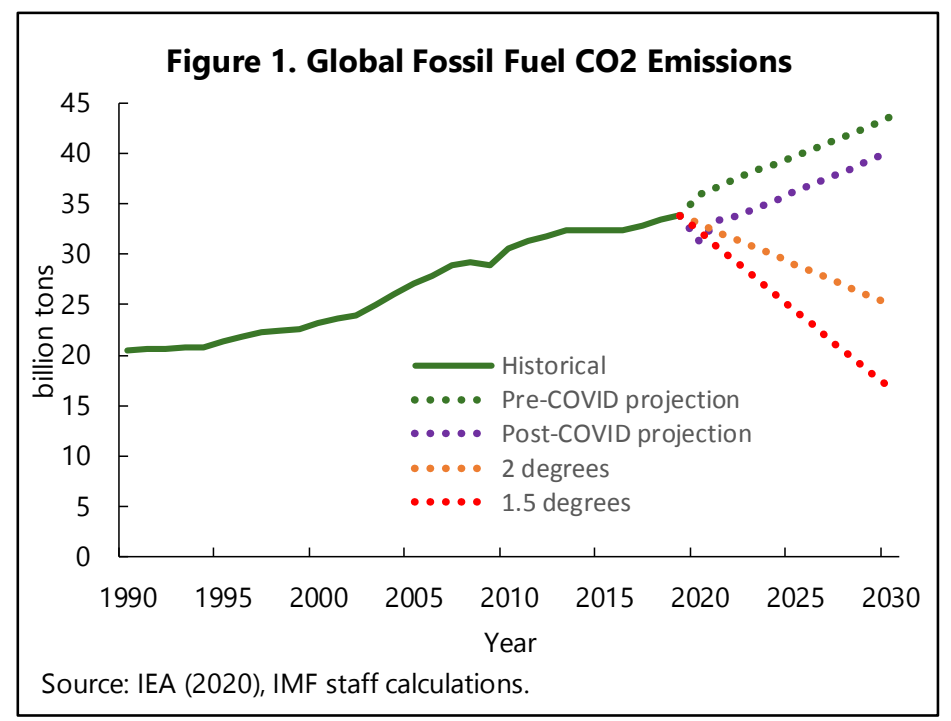
emissions in 2030 will be about 20 percent above 2018 levels, albeit moderately smaller than in pre-COVID projections (Figure 1).

\section{Nominally at least, Denmark's intermediate emissions target is significantly more stringent even than the strengthened targets announced in September 2020 for the $\mathbf{E U}$ Green Deal—namely a 55 percent emissions reduction by 2030 relative to 1990 levels. Supplementary targets (at EU and/or national level) include: ${ }^{4}$}

- A prospective ban on sales of new ICE vehicles by 2030 and replacing them largely with EVs; ${ }^{5}$

- EU standards for the fleetwide average emission rates of new passenger vehicles that decline from 130 grams $\mathrm{CO}_{2} / \mathrm{km}$ in 2015 to 65 grams $\mathrm{CO}_{2} / \mathrm{km}$ in 2030;

- Reducing non-EU ETS emissions (from transport, buildings, and agriculture) by 39 percent by 2030 relative to 2005 levels;

- Phasing out coal generation by 2030 ;

- Increasing the share of renewables in economy-wide consumption to 55 percent by 2030; and

\footnotetext{
${ }^{3}$ To net zero emissions by around 2050 and 2070 respectively for the $1.5^{\circ} \mathrm{C}$ and $2^{\circ} \mathrm{C}$ targets. See IPCC (2018).

${ }^{4}$ See NCEP (2019) for a detailed overview of Denmark's emissions objectives and a (high-level) discussion of envisioned strategies for achieving these objectives.

${ }^{5}$ Denmark led a coalition of $11 \mathrm{EU}$ countries calling for a concrete plan from the European Commissions with proposals for policy initiatives and incentives for the transition to a fleet of zero-emission passenger cars.
} 
- Improving energy efficiency by one quarter by $2030 .^{6}$

Details on how targets might be achieved are still under discussion, though stronger carbon pricing is highly likely.

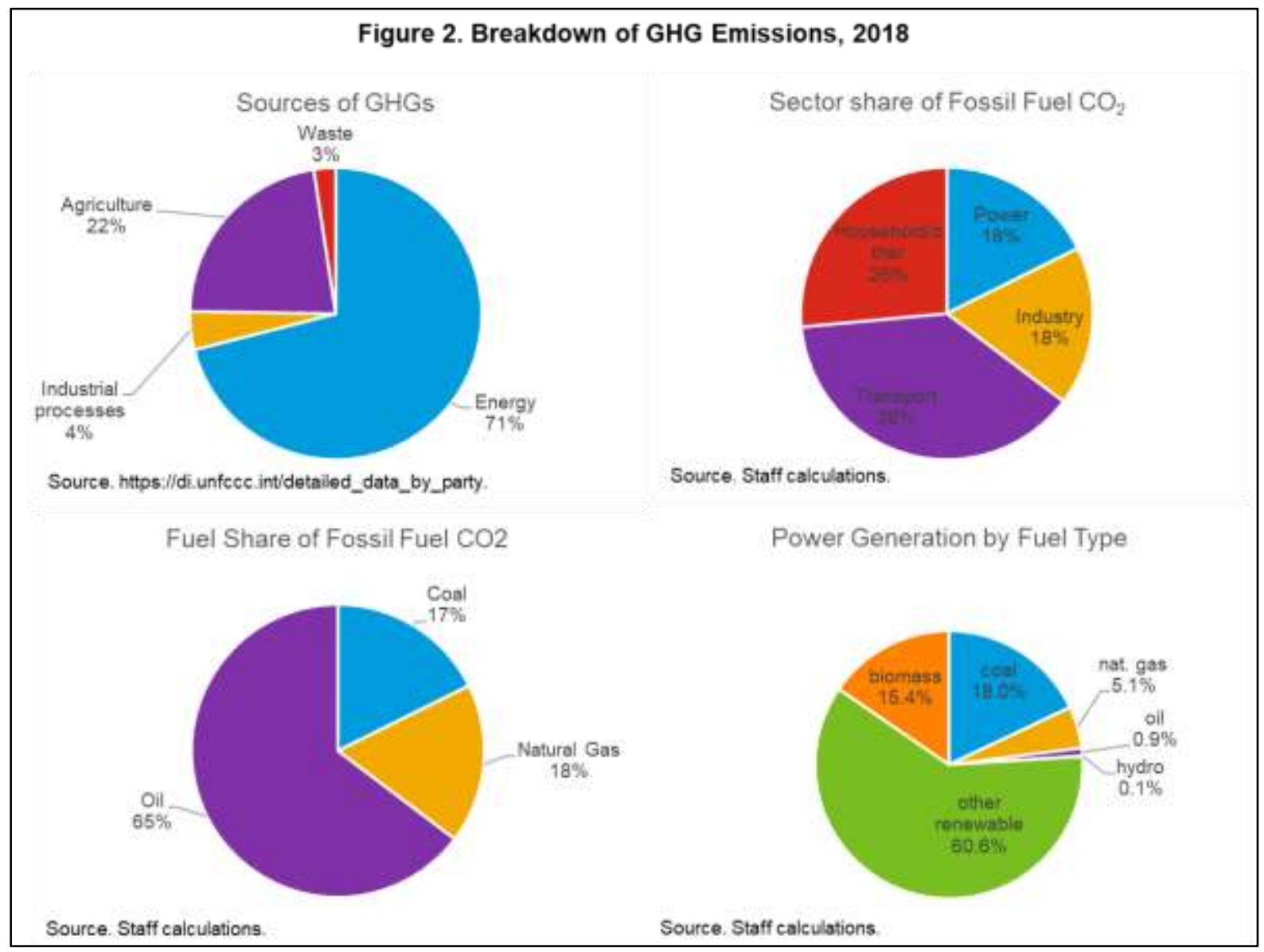

GHG emissions in Denmark (excluding land-use emissions) were 50 million tons in 2018, with 71 percent of emissions from energy (Figure 2). Agriculture accounted for 22 percent of emissions, industrial processes (e.g., cement production) 4 percent, and waste (e.g., methane leaks at landfills) 3 percent. By sector, power generation accounted for 15 percent of fossil fuel $\mathrm{CO}_{2}$ emissions, industry 21 percent, households and commercial buildings 26 percent, and transport 38 percent. By fuel type, coal accounted for 15 percent of fossil fuel $\mathrm{CO}_{2}$ emissions, oil 67 percent, and natural gas 18 percent. Biomass ${ }^{7}$ accounted for 15 percent of power generation and other renewables (on- and off-shore wind, solar) 63 percent, while coal and natural gas accounted for 16 and 5 percent respectively. Land use, land use change, and forestry (LULUCF) $\mathrm{CO}_{2}$ equivalent emissions contributed an estimated 7 million tons in $2018 .^{8}$

\footnotetext{
${ }^{6}$ See Article 1(1) and 3(4) of Directive 2012/27/EU.

${ }^{7}$ Mostly straw, wood pellets, chips, and biodegradable waste.

${ }^{8}$ From https://di.unfecc.int/detailed_data_by_party.
} 
Denmark has made substantial progress in reducing emissions (Figure 3). Fossil fuel $\mathrm{CO}_{2}$ emissions in 2018 are about half peak emissions in 1996. In a business-as-usual (BAU) scenario (i.e., with no new, or tightening of existing, mitigation policies) IMF staff project fossil fuel $\mathrm{CO}_{2}$ emissions in 2030 will be 9 percent lower than in 2018 and 37 percent lower than in $1990 .{ }^{9} \mathrm{BAU} \mathrm{CO}_{2}$ emissions growth is either positive, or emissions decline more slowly, in other EU countries. In absolute terms, $\mathrm{BAU} \mathrm{CO}_{2}$ emissions in 2030 are lower in Denmark than in other EU countries while per capita emissions are slightly lower than the EU average.

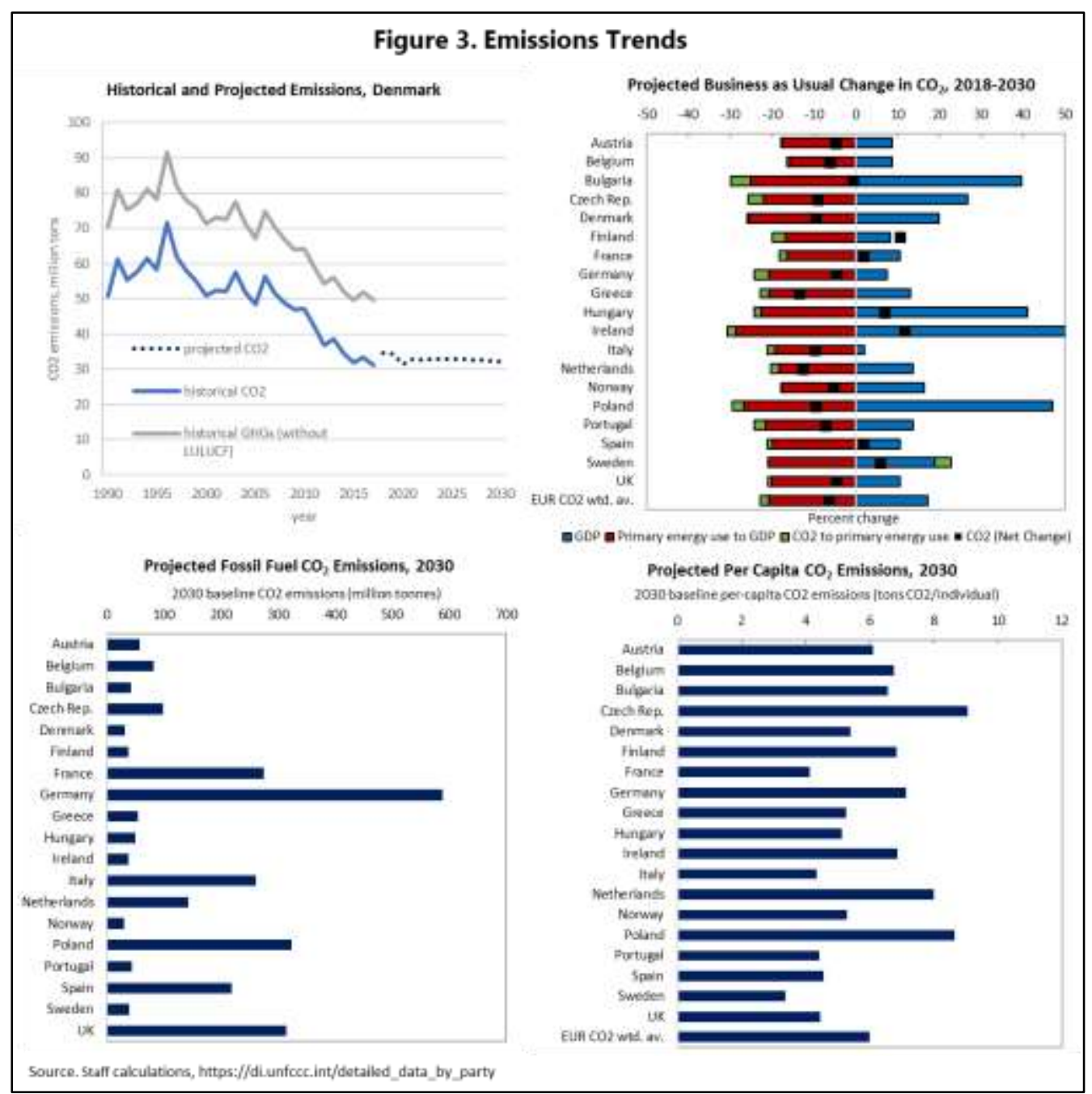

${ }^{9}$ GDP growth is more than offset by a drop in the carbon intensity of GDP reflecting improving energy efficiency, energy demand growing by less than in proportion to GDP, and growth in renewables. The Danish Climate and Energy Outlook (2019) projects GHG emissions in 2030 will be 46 percent below 1990 levels, though this includes the effects of scaling up renewable energy and energy efficiency measures. 


\section{Emissions from the power sector, district heat production, industry, and domestic} aviation, are covered by the EU ETS. EU allowance prices (as of November 2020) are around $\$ 30$ per ton. ${ }^{10}$ With a fixed cap on emissions at the EU level emissions reductions from overlapping policies in Denmark would be offset ton-for-ton by extra emissions in other EU countries (via a decline in the ETS allowance price). This problem is, to some degree, offset by the Market Stability Reserve (MSR) which withdraws allowances (sometimes permanently) when the amount of banked allowances exceeds a threshold level. But a more robust and transparent mechanism would be to underpin the EU ETS with an exogenous price floor ramping up over time. ${ }^{11}$ Higher prices could also be achieved through a higher linear reduction factor for the emissions cap - as the European Commission has suggested for delivering on the 55 percent EU climate target for 2030. EITE industries are granted free allowance allocations to address competitiveness and leakage concerns, though the European Commission is considering replacing this mechanism with a border carbon adjustment (BCA) mechanism.

\footnotetext{
${ }^{10}$ From https://ember-climate.org/carbon-price-viewer. All prices below are expressed in year $2020 \$$ or thereabouts.

${ }^{11}$ Price floors might be implemented through allowance auctions with a minimum auction price or making the MSR subject to a price trigger (see Flachsland and others 2018) - either way, allowances should be permanently withdrawn from the system whenever needed to prevent the price falling below the floor. Alternatively, the Danish government can unilaterally purchase and retire allowances to ensure domestic emissions reductions translate into reductions at the EU level, though this would involve Denmark "paying twice" for those reductions. Both elements would make the ETS more robust and transparent as well at the EU level.
} 


\section{Denmark was one of the first countries to introduce a carbon tax in 1992. The tax} covers road transportation and (non-district) heating. The current tax rate is equivalent to $\$ 26$ per ton ${ }^{12}$ which is at the top end of many carbon pricing schemes elsewhere, though Finland, Sweden, and Switzerland have prices of $\$ 68$, $\$ 119$, and $\$ 99$ per ton respectively (Table 1) and Ireland intends to raise its carbon tax to $\$ 95$ per ton by 2030.

\section{Denmark promotes EVs through incentives in the registration tax system. ICE} vehicles are subject to taxes of 85 percent for car values up to

\begin{tabular}{|c|c|c|c|c|}
\hline \multicolumn{5}{|c|}{ Table 1. Selected Carbon Pricing Schemes, 2020} \\
\hline \multirow{2}{*}{ Country/Region } & \multirow{2}{*}{$\begin{array}{c}\text { Year } \\
\text { Introduced }\end{array}$} & \multirow{2}{*}{$\begin{array}{l}\text { Price 2020, } \\
\$ / \text { Ton } \mathrm{CO}_{2}\end{array}$} & \multicolumn{2}{|c|}{ Coverage of GHGs } \\
\hline & & & Million Tons & Percent \\
\hline \multicolumn{5}{|l|}{ Carbon taxes } \\
\hline Chile & 2017 & 5 & 58 & 39 \\
\hline Colombia & 2017 & 4 & 46 & 24 \\
\hline Denmark & 1992 & 26 & 25 & 40 \\
\hline Finland & 1990 & 68 & 41 & 36 \\
\hline France & 2014 & 49 & 172 & 35 \\
\hline Ireland & 2010 & 28 & 32 & 49 \\
\hline Japan & 2012 & 3 & 909 & 68 \\
\hline Mexico & 2014 & $<1-2$ & 381 & 47 \\
\hline Norway & 1991 & $3-53$ & 47 & 62 \\
\hline Portugal & 2015 & 26 & 16 & 29 \\
\hline South Africa & 2019 & 7 & 512 & 80 \\
\hline Sweden & 1991 & 119 & 44 & 40 \\
\hline Switzerland & 2008 & 99 & 6 & 33 \\
\hline \multicolumn{5}{|c|}{ Emissions Trading Systems } \\
\hline California & 2012 & 15.3 & 375 & 85 \\
\hline China & 2021 & na & 3,453 & 26 \\
\hline European Union & 2005 & 18.5 & 2,249 & 45 \\
\hline Korea & 2015 & 33 & 489 & 70 \\
\hline New Zealand & 2008 & 14 & 45 & 51 \\
\hline Regional GHG Initiative & 2009 & 5 & 108 & 18 \\
\hline \multicolumn{5}{|l|}{ Carbon price floors } \\
\hline Canada & 2019 & 22 & 71 & 9 \\
\hline United Kingdom & 2013 & 22 & 136 & 23 \\
\hline
\end{tabular}

$\$ 32,000$ and 150 percent on value above that. For gasoline cars, the registration tax is reduced by $\$ 640$ for each $\mathrm{km} /$ liter below $20 \mathrm{~km} /$ liter and increased by $\$ 960$ for each $\mathrm{km} / \mathrm{liter}$ above $20 \mathrm{~km} /$ liter. The same schedule applies to diesel cars with the pivot point at $22 \mathrm{~km} / \mathrm{liter}$. EVs up to $\$ 63,500^{13}$ are exempt from registration fees and pay only a fraction of the registration tax on vehicle value above this threshold - 20 percent in 2020, 65 percent tin 2021, 90 percent in 2022 and 100 starting in 2023. Registration taxes currently raise revenue of about 1 percent of GDP. ${ }^{14}$

\footnotetext{
12 This abstracts from pre-existing road fuel taxes.

${ }^{13}$ For comparison a Tesla Long Range AWD Model 3 is comparable to an Audi A5 but the base price for the former is $\$ 75,000$ while that for the latter is $\$ 40,000$ - the price gaps is closing all the time however, not least because the capacity of electric batteries is increasing, while battery prices are falling. 4,618 (private and commercial) EVs were purchased in 2019 but EVs are still less than 2 percent of the on-road fleet. Figures are from Automobile Commission (2020).

${ }^{14}$ Ownership taxes are also paid semi-annually with rates varying between $\$ 53$ (for vehicles with fuel economy above $50 \mathrm{~km} /$ liter) and $\$ 1,870$ (for vehicles with fuel economy below $4.4 \mathrm{~km} /$ liter). EVs are classified at the top of the fuel economy scale.
} 
Denmark also imposes significant road fuel taxes. Gasoline excises are $\$ 0.74$ per liter, equivalent to $\$ 320$ per ton $\mathrm{CO}_{2}$, while (road) diesel excises are $\$ 0.50$ per liter $(\$ 185$ per ton of $\left.\mathrm{CO}_{2}\right) .{ }^{15}$ Retail gasoline and diesel prices for Denmark are, nonetheless, barely half the levels needed to fully reflect supply and environmental costs (excluding global warming), and value added tax (VAT) - higher levels of fuel taxation, which have been recently proposed ${ }^{16}$, are therefore warranted. ${ }^{17}$ Coal is not directly taxed, though estimated local air pollution costs from coal generation in Denmark are not that large-US \$1.9 per gigajoule (GJ), equivalent to $\$ 19$ per ton of $\mathrm{CO}_{2}$. In general, other countries also undercharge for fossil fuels (Figure 4). ${ }^{18}$

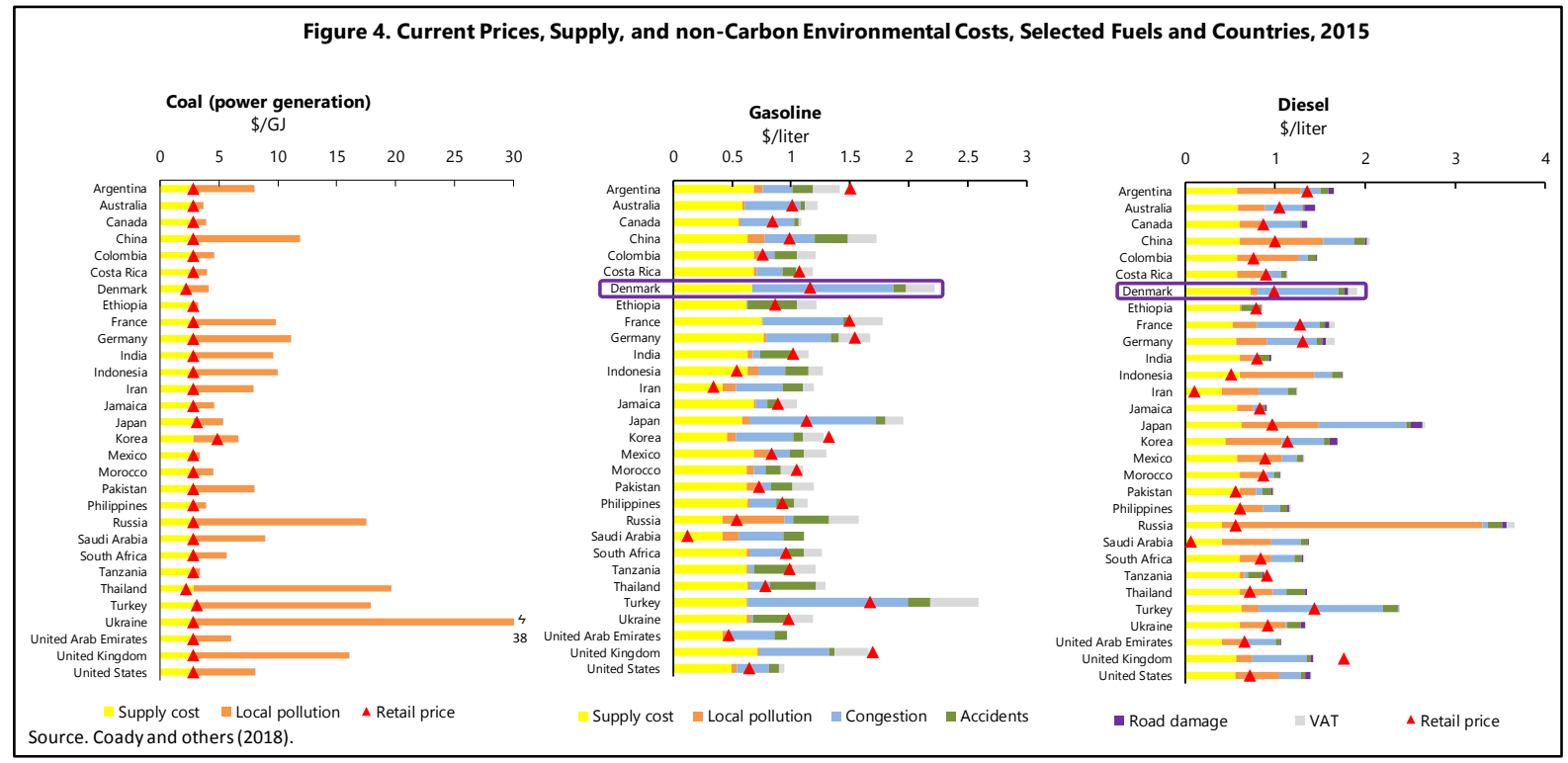

Other mitigation actions involve a mix of regulatory and voluntary measures for renewables and energy efficiency. Technology-neutral renewable energy tenders are being offered to promote renewable generation investment (notably offshore wind). Numerous

\footnotetext{
${ }^{15}$ IEA (2019), pp. 94-95.

${ }^{16}$ For example, Automobile Commission (2020) proposed a fuel tax increase of \$0.16 per liter starting in 2021.

${ }^{17}$ Some level of fuel taxation is efficient to reflect external costs of driving, including traffic congestion, accidents, local air pollution, and road maintenance - at least until more efficient instruments like km-based charging systems are comprehensively applied (see below and Parry and others 2014 on methodologies for quantifying externalities and efficient fuel taxes). Although the registration tax system provides incentives for smaller (i.e., lower value) vehicles and EVs, unlike road fuel taxes, it does not provide incentives to economize on vehicle use.

${ }^{18}$ Denmark also imposes taxes on the energy content of oil products, natural gas, and coal used outside the power sector. A Public Service Obligation Scheme has also imposed a levy on electricity paid by all consumers (where revenues have funded renewables) though this levy is phasing out between 2017 and 2021.
} 
information dissemination programs inform households and firms about the benefits of energy-saving investments. ${ }^{19}$

Supporting investment and technology policies are also needed. Up to $\$ 43 \mathrm{bn}$ (equivalent to 12 percent of 2019 GDP) has been allocated for two offshore wind islands projects, though more generally new investment in renewables will be redirected (away from investment in fossil fuel plants) and much of it will be private rather than public. The government has also allocated \$4.6bn for green renovations of public housing from 2021-26 and \$0.17 bn for basic research into critical technologies (e.g., battery storage for intermittent renewable power). Estimated infrastructure costs for developing EV charging stations are relatively small, under $\$ 1 \mathrm{bn} .^{20}$

\section{Emissions from livestock and crop production cannot be taxed directly but proxy pricing schemes are feasible using data routinely collected on farm-level operations.} Enteric fermentation in (beef and dairy) cattle herds produces methane emissions, manure management releases methane and nitrogen oxide emissions, and crop production (e.g., via fertilizers/pesticides) releases nitrogen oxide emissions. Farm-level data on livestock, feed, crop production, fertilizer/pesticide use, and acreage can be combined with emission rate data $^{21}$ to indirectly estimate emissions.

\section{Advantages and Limitations of the Existing Policy Framework}

Carbon pricing has a critical role but getting design details right is key. Pricing:

- Provides across-the-board incentives to reduce energy and shift to cleaner fuels (by reflecting the cost of carbon emissions in the prices of fuels, electricity, and goods);

- Automatically minimizes mitigation costs (by equalizing the cost of the last ton reduced across fuels and sectors);

- Redirects new investment to clean technologies (by establishing a robust price signal);

- Mobilizes government revenue;

- Generates domestic environmental benefits (e.g., reductions in local air pollution mortality, traffic congestion); and

\footnotetext{
${ }^{19}$ NCEP (2019), Table 8.

${ }^{20}$ Staff calculation based on: (i) the average cost of charging stations in McKinsey (2018) (about \$1,150 per station); (ii) an assumption that one charging point is needed for each five vehicles (Ministry of Transport Building and Housing 2017); and (iii) the eventual size of the EV fleet is the same as the current vehicle fleet.

${ }^{21}$ IPCC (2006).
} 
- Can be straightforward administratively (especially if it builds off institutional capacity for existing policies).

But pricing should:

- Have comprehensive coverage and uniform prices;

- Provide a predictable and rising price;

- Exploit fiscal opportunities; and

- Be compatible with overlapping instruments that are likely needed to enhance overall policy acceptability.

The EU ETS and Denmark's domestic carbon tax perform well on some, but not all, of these criteria.

EU and domestic pricing together are comprehensive, but prices are not harmonized and do not automatically ramp up over time. The EU ETS and domestic carbon tax cover the major (non-agricultural) emissions sources. Although (with MSR reform) EU ETS allowance prices have increased recently, future prices are uncertain, the domestic carbon tax rate is fixed, and there is no mechanism in Denmark for linking prices across the ETS and non-ETS sectors.

The EU ETS and domestic carbon tax do not fully exploit revenue opportunities for the general budget in Denmark. EU ETS allowances are partly given away for free and partly auctioned with revenues used for environmental purposes while much of the revenue from Denmark's carbon tax is used for environmental spending and industry compensation. Diverting revenue from the general budget that could have been used to boost the economy (e.g., by cutting taxes on labor and capital that harm incentives for work effort and investment) might increase the overall costs of carbon pricing, depending on the social value of the environmental spending.

\section{Denmark's mitigation target implies a 52 percent reduction in emissions below}

projected BAU levels in 2030. This reduction is highly ambitious, though if other EU countries were to cut their emissions to 55 percent below 1990 level in 2030, the reductions below 2030 BAU levels would be comparable to those in Denmark in some cases (compare the green dots for other countries to the yellow dot for Denmark in Figure 5). 
Figure 5. Reduction in Fossil Fuel $\mathrm{CO}_{2}$ from Emission Targets and Carbon Pricing in 2030, Selected Countries

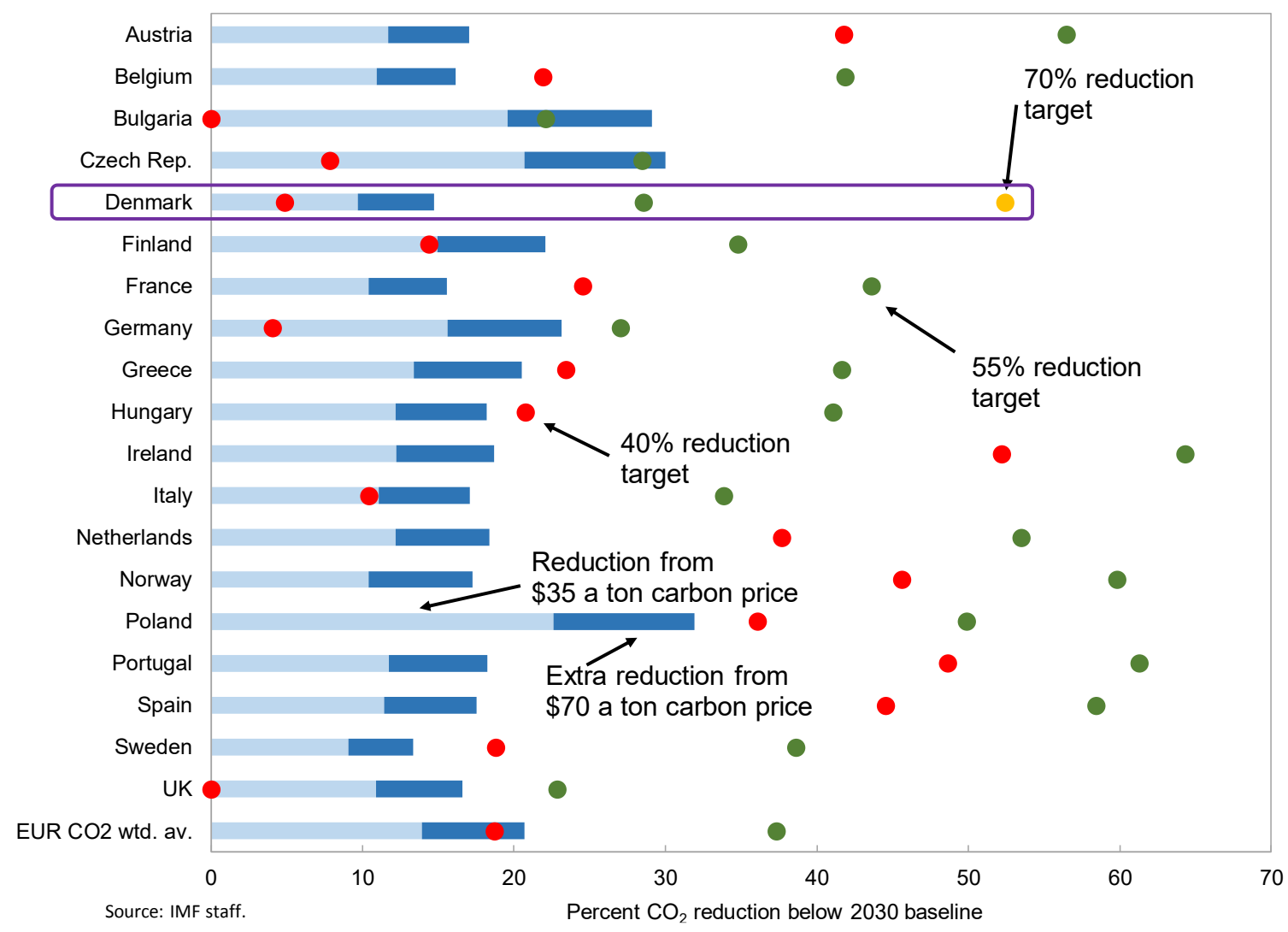

Even aggressive carbon pricing by itself falls well short of achieving Denmark's emission reduction target. For example, carbon prices of $\$ 35$ and $\$ 70$ in 2030 reduce fossil fuel $\mathrm{CO}_{2}$ emissions 10 and 15 percent respectively below baseline levels with no pricing (see the blue bars in Figure 6). Even a $\$ 100$ per ton carbon price in 2030 reduces emissions 19 percent below BAU levels, less than half of the needed reduction. The power, transport, industry, and household sectors contribute $31,13,30$, and 26 percent to this emission reduction respectively. ${ }^{22}$ Recent estimates suggest emissions prices of $\$ 200-250$ per ton will be needed for the 70 percent target in 2030 and the resulting economic costs amount to less than one percent of GDP. ${ }^{23}$ There is, however, considerable uncertainty over whether this level of pricing will be acceptable, as it would likely put Denmark well out in front of other countries (Table 1). There are also huge uncertainties surrounding estimates of the needed carbon pricing due, for example, to uncertainty over the future availability and costs of clean technologies. Both considerations imply a role for reinforcing mitigation instruments at the sectoral level that are less efficient than pricing but can: (i) have greater acceptability; (ii) provide some 'insurance' if the emissions impacts of carbon pricing turn out to be smaller

\footnotetext{
${ }^{22}$ If agricultural emissions were also priced the proportionate reduction in nationwide emissions would likely be greater.

${ }^{23}$ Danish Council on Climate Change (2020), Ministry of Climate, Energy and Utilities (2020).
} 
than projected; and (iii) be quickly adjusted if needed depending on progress towards emissions targets.

The price responsiveness of emissions in Denmark is somewhat more limited than in most other EU countries (Figure 5). This reflects in part the progress already made in sectors (like power generation) that are easier to decarbonize.

\section{A Comprehensive PaCkage to Enhance the Effectiveness of Pricing and ADDRESS BURDENS ON HOUSEHOLDS AND FIRMS}

Denmark should scale up carbon pricing as much as practically feasible. Pricing can be strengthened and made more cost effective by: (i) imposing a domestic surcharge on emissions covered by the EU ETS set such that the surcharge equals the difference between an escalating price target and the ETS allowance price; and (ii) automatically increasing the domestic carbon tax in line with the price target for emissions in the ETS sector. The surcharge would resemble the UK Carbon Price Floor, which imposes a national level variable tax (set three years in advance) on power sector emissions, equal to the difference between an exogenous target price and the projected EU ETS price. ${ }^{24}$ The Netherlands is implementing a similar scheme for entities in the power and industrial sectors. ${ }^{25}$

\section{But a comprehensive package of complementary measures is needed to increase environmental effectiveness and address burdens on households and firms. This section discusses: (i) feebates to reinforce pricing at the sectoral level; (ii) household incidence analysis to inform equitable design and use of carbon pricing revenue; and (iii) measures to address competitiveness impacts. Other elements of a reform package can increase effectiveness and acceptability but are less amenable to quantitative analysis. ${ }^{26}$}

\section{A. Reinforcing Carbon Pricing with Feebates}

To the extent it is constrained on acceptability grounds, carbon pricing can be reinforced at the sectoral level with feebates, most importantly for transport, but

\footnotetext{
${ }^{24}$ The current tax is $£ 18$ (\$23) per tonne. See Hirst (2018).

${ }^{25}$ Government of the Netherlands (2019). At the EU level, the Danish government is pushing for a strengthening and expansion of the ETS to other sectors ahead of the review of the ETS directive in summer of 2021 (see www.eu.dk/samling/20191/almdel/EUU/bilag/794/2217947.pdf).

${ }^{26}$ These include: (i) a clearly announced and gradually rising carbon price trajectory which allows households and firms time to adjust (e.g., by making energy-efficiency investments); (ii) extensive consultations with stakeholders to build support for the reform and an effective communications program informing the public of the rationale for reform; (iii) assistance measures for vulnerable regions and workers; and (iv) complementary clean energy infrastructure investments. See Clements and others (2013) and Coady and others (2018) for further discussion.
} 
potentially also for other sectors. Feebates apply a sliding scale of fees to products or activities with above average emission rates (or increases in emissions over time) and a sliding scale of rebates to products or activities with below average emission rates (or reductions in emissions over time). Potential applications include:

- Transportation: New vehicle sales could be subject to a fee equal to the product of (i) a $\mathrm{CO}_{2}$ price; (ii) the difference between the vehicle's $\mathrm{CO}_{2} / \mathrm{km}$ and the average $\mathrm{CO}_{2} / \mathrm{km}$ of the new vehicle fleet; and (iii) the average lifetime use of a vehicle (in discounted $\mathrm{km})$.

- Industry: firms (currently covered by the EU ETS) could pay a fee equal to the product of (i) a $\mathrm{CO}_{2}$ price; (ii) the difference between the firm's $\mathrm{CO}_{2}$ per unit of production and the industry average $\mathrm{CO}_{2}$ per unit of production; and (iii) their production level.

- Electricity production: generators could pay a fee equal to the product of (i) a $\mathrm{CO}_{2}$ price; (ii) the difference between their $\mathrm{CO}_{2}$ /kilowatt hour ( $\mathrm{kWh}$ ) averaged across their plants and the industry-wide average $\mathrm{CO}_{2} / \mathrm{kWh}$; and (iii) their electricity output.

- Energy-consuming products: refrigerators, heating systems, and other energyconsuming products could incur a fee equal to the product of (i) a per unit energy charge; and (ii) the difference between their energy consumption rate and the industry-wide energy consumption rate for that product. ${ }^{27}$

- Land-use: forest and agricultural landowners could be subject to a fee equal to the product of (i) a $\mathrm{CO}_{2}$ price; (ii) the difference between stored forest carbon on their land in a baseline year and stored carbon in the current year. ${ }^{28}$

Feebates are effective... For example:

- Vehicles: feebates would promote the full range of opportunities for shifting from high- to low-emission rate ICEs, from ICEs to biofuel and hydrogen vehicles, and

\footnotetext{
${ }^{27}$ For refrigerators, for example, the energy consumption rate is $\mathrm{kWh} /$ cubic foot cooled. Promoting electricity conservation is still important, even if power generation were decarbonized, to ensure demand/supply balance given constraints on renewable generation sites.

${ }^{28}$ Capacity for measuring forest carbon inventories from a combination of satellite imagery, aerial photography, and on-the-ground tree sampling is presently being developed in many countries, for example, for 47 tropical countries under the REDD+ Readiness program (see www.forestcarbonpartnership.org/readiness-fund-0). Over time the program might be expanded to include carbon stored in soils as metering technologies evolve.
} 
from ICEs to EVs (the vehicle registration tax system promotes only the last response in an effective way); ${ }^{29}$

- Forestry: feebates promote afforestation and enhanced forest management ${ }^{30}$ and discourage deforestation (a subsidy for forestland preservation promotes only the last response).

...cost-effective... Feebates provide the same incremental reward for reducing emissions across firm and household responses and feebates in different sectors and could be harmonized to promote economy-wide cost effectiveness. ${ }^{31}$ Regulatory approaches, or approaches targeted on specific technologies, generally promote fewer responses and are difficult to coordinate cost effectively across firms, households, sectors, and different periods of time (at least without extensive credit trading provisions).

...do not lose revenue and do not impose a first-order burden on the average household or firm... Feebates are revenue neutral so long as: (i) the 'pivot point' (the point above/below which fees/rebates are applied) equals the industry or product average emission or energy consumption rate (or baseline forest carbon storage); and (ii) the pivot point is automatically updated over time so that fees collected pay for the rebates..$^{32}$ In contrast, EV and renewable subsidies impose a fiscal cost. Another possibility - which has equivalent effects on the relative price of vehicles as an (equivalently scaled) feebate - is simply to levy (some portion of) vehicle taxes in direct proportion to vehicle emission rates $^{33}$ but this approach does not stabilize the revenue base (revenues decline over time as the fleetwide average emission rate declines). Revenue-neutrality under feebates also implies no first-order effect on the prices of products with average emission rates (as would occur under carbon pricing, prior to revenue recycling), which may enhance acceptability.

...and, in general, build off existing capacity and data. For example, feebates are easily integrated into registration fee formulas. And accurate data on both firm- and product-

\footnotetext{
${ }^{29}$ More expensive vehicles pay more tax, but $\mathrm{CO}_{2}$ emission rates are only loosely related to vehicle prices.

${ }^{30}$ For example, postponing timber harvesting, planting of larger trees, thinning to increase forest growth, fertilizing. See Parry (2020) for more discussion on the rationale for, and design of, feebates for the forestry sector.

${ }^{31}$ Meeting sectoral targets (e.g., EVs) will imply some differentiation of carbon prices. This need not increase economywide mitigation costs very much however, if the sector with lower prices (e.g., power) is only a small share of nationwide emissions.

${ }^{32}$ An alternative would be to base the pivot point on EU average emission rates which this would help mitigate carbon leakage, since Danish firms would be rewarded to the extent that their emission rates are low relative to their (EU) trading partners which is especially advantageous in the absence of a BCA.

${ }^{33}$ This is proposed in Automobile Commission (2020).
} 
specific emission rates, and industry-wide emission rates, is available for fossil fuel $\mathrm{CO}_{2}$. In the forestry sector, crude estimates of forest carbon inventories can be obtained using a combination of satellite imagery, aerial photography, and on-the-ground tree sampling (e.g., on age distribution, tree sorts, soil characteristics).

The case for feebates in Denmark is compelling for transportation. The vehicle sector is the largest source of emissions, strong incentives are needed to promote EVs, and without eroding the valuable revenue base from vehicle taxation. In contrast, much of power generation has already been decarbonized and this trend is set to continue in future with the phase out of coal and expansion of renewables, implying less need to reinforce incentives with feebates. In addition, there is not much heavy industry in Denmark - for example, there is only one producer of cement and sugar, two refineries, and no producers of steel and aluminum. Nonetheless, a modified feebate could still provide mitigation incentives without a difficult (from an acceptability, competitiveness, and leakage perspective) first order tax burden for these firms. ${ }^{34} \mathrm{~A}$ feebate is potentially applicable to industrial firms whose activities directly release emissions and who are currently covered by the EU ETS - a feebate would not be applicable to industries whose emissions are only indirect (e.g., embodied in the electricity used in producing beverages).

For illustration a feebate of $\$ 1,000$ for vehicles would provide a subsidy of $\$ 14,000$ for $E V s$ while imposing a tax of $\$ 7,500$ on a vehicle with 145 grams $\mathrm{CO}_{2} / \mathbf{k m}$ (see Table 2). This assumes the new vehicle fleetwide $\mathrm{CO}_{2}$ emission rate, or pivot point, is currently 95 grams $\mathrm{CO}_{2}$ per $\mathrm{km}$ (in line with EU standards). EV subsidies would decline over time as the pivot point declines, which is appropriate as the costs of EVs fall over time. ${ }^{35}$ Several countries have recently introduced feebates for the vehicle sector including France, the Netherlands, and Norway (and many others have elements of feebates). ${ }^{36}$

\section{A feebate that progressively shifted new sales to 100 percent EVs zero-emission vehicles by 2030}

\begin{tabular}{|c|c|c|c|c|}
\hline \multirow{3}{*}{$\begin{array}{c}\text { new vehicle } \\
\text { emissions } \\
\text { grams } \mathrm{CO}_{2} / \mathrm{km}\end{array}$} & \multicolumn{2}{|c|}{$\begin{array}{l}\text { Feebate: pivot point } 95 \mathrm{~g} \\
\mathrm{CO} 2 / \mathrm{km}^{\mathrm{a}}\end{array}$} & \multicolumn{2}{|c|}{$\begin{array}{c}\text { Feebate: pivot point } 65 \mathrm{~g} \\
\mathrm{CO} 2 / \mathrm{km}^{\mathrm{a}}\end{array}$} \\
\hline & \multicolumn{4}{|c|}{$\$ /$ ton $\mathrm{CO} 2$} \\
\hline & 500 & $\begin{array}{c}1000 \\
\text { change in pu }\end{array}$ & $\begin{array}{c}500 \\
\text { hase price, } \$\end{array}$ & 1000 \\
\hline 145 & 3,731 & 7,461 & 5,969 & 11,938 \\
\hline 135 & 2,985 & 5,969 & 5,223 & 10,446 \\
\hline 125 & 2,238 & 4,477 & 4,477 & 8,954 \\
\hline 105 & 746 & 1,492 & 2,985 & 5,969 \\
\hline 95 & 0 & 0 & 2,238 & 4,477 \\
\hline 85 & -746 & $-1,492$ & 1,492 & 2,985 \\
\hline 75 & $-1,492$ & $-2,985$ & 746 & 1,492 \\
\hline 65 & $-2,238$ & $-4,477$ & 0 & 0 \\
\hline 55 & $-2,985$ & $-5,969$ & -746 & $-1,492$ \\
\hline 0 & $-7,088$ & $-14,177$ & $-4,850$ & $-9,700$ \\
\hline
\end{tabular}

\footnotetext{
${ }^{34}$ For a single-firm industry, the firm could be taxed on the difference between its emission rate and a target emission rate with the latter becoming progressively more stringent over time.

${ }^{35}$ In fact, the price of EVs should not be too low as this might encourage car ownership among households that previously relied on other transport modes.

${ }^{36}$ See, for example, ACEA (2018), Bunch and others (2011), pp. 59-61.
} 
would reduce road fuel emissions by 35 percent in $2030 .{ }^{37}$ Deeper reductions would continue after 2030 as the fleet continues to turn over. ${ }^{38}$

\section{A feebate could be integrated into the current vehicle registration tax system while progressively scaling back the current exemption for EVs-environmental and fiscal objectives could then be met simultaneously. Currently, the more successful tax emptions for EVs are in promoting EV sales the less revenue is raised from registration fees. In contrast, a feebate system can be combined with a registration tax on all vehicles with the former set to meet environmental objectives and the latter set to meet fiscal objectives without a tension between environmental and fiscal objectives.}

The phase out of ICEs could be complemented by the phase in of $\mathbf{k m}$-based taxation to maintain revenue and manage road congestion. Revenue from road fuel taxes in Denmark (currently 1 percent of GDP) will decline as ICEs are phased out. Progressively replacing fuel taxes with $\mathrm{km}$-based charging for all vehicles could provide a robust revenue base to replace fuel tax revenue while much more effectively reducing traffic congestion, which imposes estimated costs of \$3.1 billion in 2017 (about 1 percent of GDP). ${ }^{39}$ This congestion imposes significant external costs on road users and is excessive because motorists do not account for their impact on slowing road speeds for other road users. Per km tolls on busy roads, rising and falling over the rush hour, exploit all behavioral responses for reducing congestion. ${ }^{40}$ Developments in metering technologies such as global positioning systems (GPS) imply that people's driving could be tracked and billed accordingly, though the technology still needs further development and national-level testing. ${ }^{41} \mathrm{~km}$-based charging might be promoted through subsidizing/taxing sales of vehicles with/without monitoring capacity during a transition period with monitoring capacity eventually becoming mandatory.

\footnotetext{
${ }^{37}$ This assumes 7 percent of the fleet is replaced each year (i.e., vehicle lifespans are 15 years) and initially 2 percent of new vehicle sales are EVs, rising linearly to 100 percent by 2030.

${ }^{38}$ In principle, the emissions impacts of feebates could be estimated using cross-price elasticities between EVs and conventional vehicles but there is not much solid evidence on this to date and most likely the elasticity will increase in future as, for example, EVs become more reliable and charging infrastructure expands.

${ }^{39}$ From www.thelocal.dk/20171215/denmark-wastes-20-billion-kroner-on-traffic-delays-report.

${ }^{40}$ For example, setting off before or after the peak of the rush hour, shifting to off-peak travel, less congested roads, or public transport, carpooling, reducing trip frequency.

${ }^{41}$ Automobile Commission (2020). Information on people's driving patterns could be collected by a private firm which passes on only information about motorists' total tax liability to the government to help address privacy concerns.
} 


\section{B. Promoting Equitable Pricing Reform}

\section{Understanding the equity impacts of carbon pricing reform requires household}

incidence analysis. The household incidence or burden of carbon pricing depends on several channels. ${ }^{42}$ These include: (i) the direct effect of higher energy prices; (ii) the indirect effect of higher prices for other consumer goods (due to the higher cost of domestic energy inputs); (iii) changes in wages in trade-exposed sectors that cannot pass forward higher energy input costs to international markets; and (iv) how households benefit from the recycling of carbon pricing revenues. ${ }^{43}$

\section{Carbon pricing has} disproportionately large impacts on natural gas prices in Denmark and modest impacts on electricity and road fuel prices. For example (see Figure 6), a $\$ 100$ per ton carbon price in 2030 would increase gas prices 60 percent (the proportionate impact on coal prices is larger still but coal is not directly consumed by households). Retail gasoline and electricity prices would only rise by 11 and 4 percent respectively ${ }^{44}$ - the small electricity
Figure 6. Energy Price Impacts of Carbon Price, 2030 (Percent increase relative to BAU)

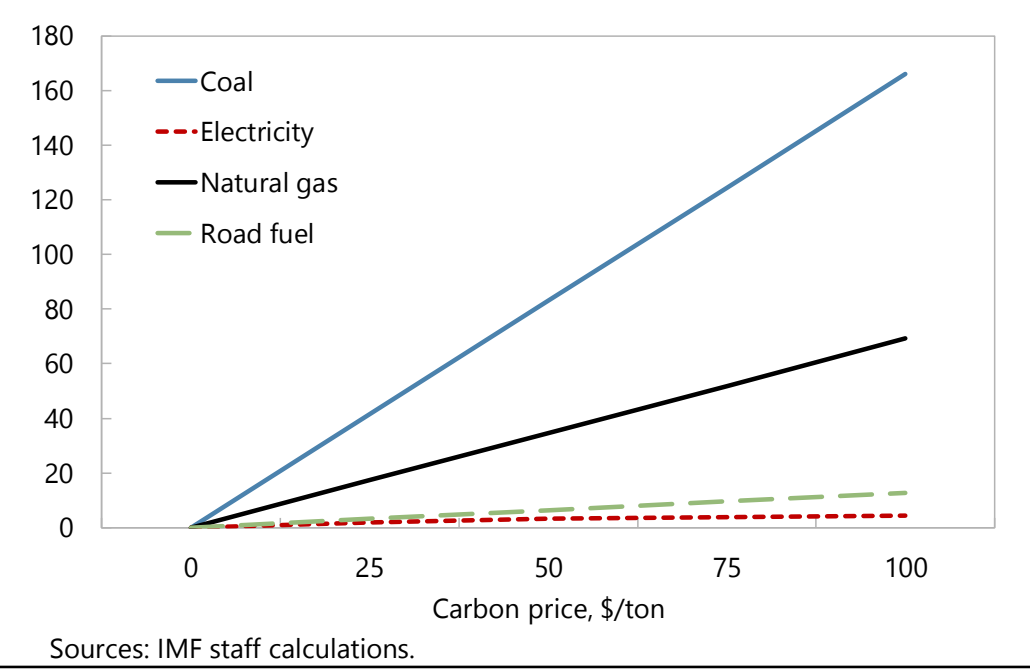

${ }^{42}$ See Coady (2006) for a discussion in the context of energy price reforms.

${ }^{43}$ The full pass back to wages for exporters is consistent with mobile capital and firms and with exporters being price-takers on world markets. Changes in wages and the return to capital might also result from general equilibrium effects as production is re-allocated from carbon intensive activities to other sectors that may have different capital to labor ratios, but these effects are difficult to predict. As an approximation, it seems reasonable to assume carbon pricing for other (non-trade-exposed) sectors is fully passed forward to domestic users given that energy demand curves tend to be inelastic while (medium to longer term) energy supply curves tend to be elastic. Consistent with this, changes in gasoline and diesel prices tend to be fully passed forward in advanced countries (IMF 2020, pp. 4) while carbon pricing tends to be fully reflected in higher consumer prices for electricity in EU countries (e.g., Sijm and others 2012).

${ }^{44}$ A $\$ 100$ carbon tax increases retail prices for gasoline and diesel by $\$ 0.23$ and $\$ 0.27$ per liter respectively (relative to no carbon tax) which is smaller than price fluctuations due to changes in international oil prices. For comparison, a decline in international oil prices from their peak of $\$ 100$ per barrel in 2014 to their current level of about $\$ 40$ per barrel, reduced retail gasoline and diesel prices by about $\$ 0.50$ per liter. 
price impact reflects the large share of zero-carbon fuels in generation (and the phase out of coal). ${ }^{45}$
A higher carbon price affects household welfare, prior to behavioral responses, largely in proportion to energy consumption. The direct impact of an energy price increase resulting from a higher carbon price, expressed as a percentage of total household consumption, can be calculated as: ${ }^{46}$

\section{Direct impact $=$ budget share $*$ percentage increase in energy price}

If the budget share for a certain energy product is 0.05 for example, a 10 percent increase of the price of this item will result in a decrease in real income for the household equivalent to 0.5 percent. We use Eurostat tables on the structure of consumption expenditure for 48 aggregated categories of goods and services by income quintile for 2015 (the latest available year) and assume these budget shares apply for 2030. Budget shares are adjusted for under-reporting of consumption in household surveys by scaling consumption in the denominator to be equivalent to household consumption in the national accounts. ${ }^{47}$ On average, energy and fuel consumption accounts for 6.2 percent of total household consumption in Denmark, moderately lower than in most other European countries (see Figure 7).

\section{Households across the income distribution in Denmark spend broadly the same on energy as a share of total consumption, but the composition of spending varies. The}

\footnotetext{
45 These small price impacts imply that carbon pricing will probably do little to discourage the electrification of transportation and other sectors.

46 See Coady (2006).

47 Treatment of imputed rent for owner-occupied housing and some financial services are the main source of discrepancies (see Eurostat 2020 for details). For 2015 in Denmark, the ratio of total household consumption expenditure as estimated from the household budget survey to the national accounts was 0.89 .
} 
bottom quintile spends disproportionately more on electricity and natural gas, while higher income households spend more on road fuels.

Indirect incidence impacts are calculated assuming increases in energy production costs are fully and immediately passed forward onto the domestic prices of goods and services. We use an inputoutput table for Denmark for 2014 (see Annex I) to calculate how sectoral prices change in response to higher domestic energy input prices and assume these price impacts would be the same

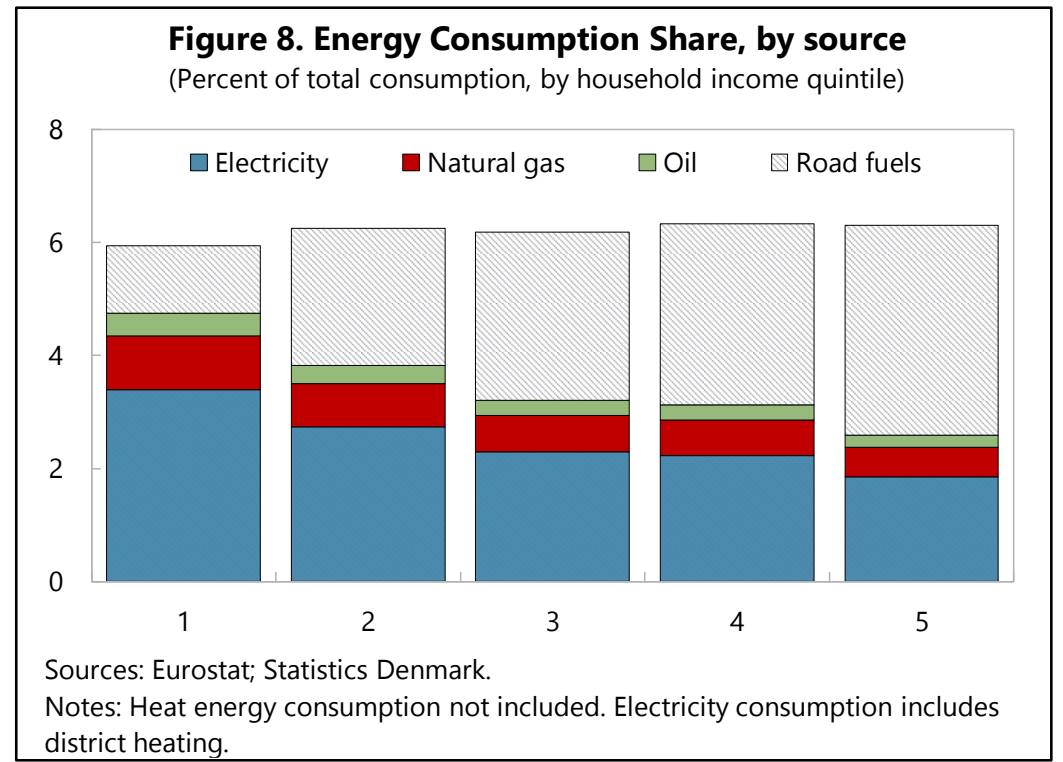

district heating.

in 2030. These sectoral price changes are then matched to the household consumption tables to calculate changes in purchasing power by income groups arising from both the direct and indirect channels. The calculations assume the prices of non-energy intermediate and final imports stay constant when domestic energy prices increase..$^{48}$ Importantly, assuming constant household budget shares and carbon intensities of production will lead us to overestimate incidence of the carbon tax in 2030 as higher energy prices and technological developments over the next decade will lower demand for carbon.

Finally, households are also affected by changes in wages. Given different energy intensity of production, labor income shares, and exposure to trade, higher energy prices lead to different changes in wages across sectors. We calculate the pass back of higher domestic energy input costs for exporting firms by sector using the input-output table. We then use the associated sectoral wage changes multiplied by the share of output that is exported and match them to household survey data to calculate how they affect different household income groups.

\footnotetext{
${ }^{48}$ Under a full BCA with export rebates, the price of imports increases in proportion to their carbon content, while wages paid by exporting firms are unaffected. If foreign production is more carbon intensive than domestic production - which is the case for Denmark - then the incidence on households through higher consumer prices would be larger. Accurately estimating this incidence would require inter-country input-output tables with country-sector specific carbon emission intensity of production.
} 
Prior to revenue use, a carbon tax of $\$ 100$ per ton of $\mathrm{CO}_{2}$ in 2030 imposes an average burden on households of 1.8 percent of consumption and is moderately progressive. ${ }^{49}$ The purchasing power of households in the lower quintile would decrease by 1.6 percent of total consumption. This is largely driven by the higher price for natural gas, an important energy source for heating, and by reduced wages for low-income workers in the tradable sector. Higher prices for electricity and road fuels also contribute to reducing real incomes, but only modestly. The indirect effect from non-energy goods contributes a more significant 0.4 percent decline in purchasing power. At the other end of the income scale, households in the top 20 percent see a somewhat larger erosion in purchasing power of 2 percent, with a larger impact resulting from: (i) higher road fuel prices (due to higher propensity of wealthier households to drive rather than use other transport modes); and (ii) lower wages (the ratio of wages to consumption generally rises with higher household income). The indirect effect from higher prices of non-energy goods is moderately smaller for this group of households.

\footnotetext{
${ }^{49}$ Wier and others 2005 and Danish Economic Councils 2009 find similar results from green taxes in Denmark when households are classified according to consumption levels.
} 


Alleviating burdens on
households can be done at
little fiscal cost. In the
scenario under
consideration, the carbon
tax collects around 0.7
percent of GDP in revenues
in 2030 , or 1.6 percent of
consumption, which falls
short of the average
incidence by 0.2 percent of
consumption. ${ }^{50}$ This means
that in aggregate, the
incidence arising from the

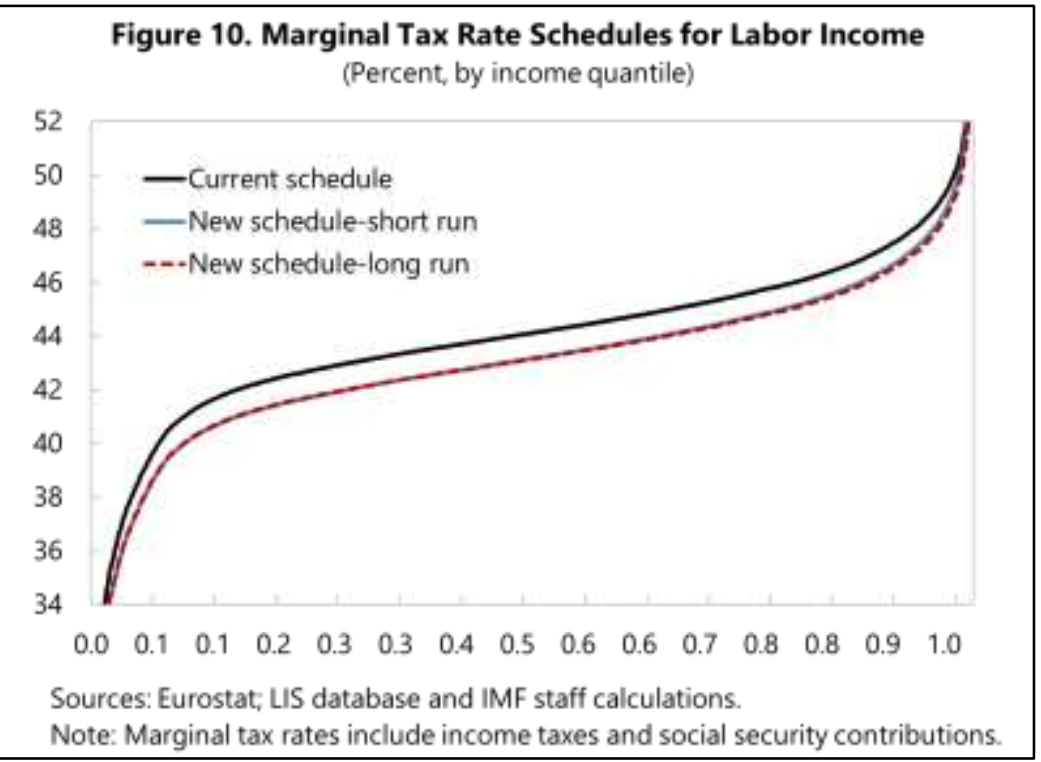

carbon tax can be fully

offset at fairly modest

additional fiscal cost. This

could be done by

transferring the proceeds of

the carbon tax, along with a

modest top up from general

funds, back to households

in the form, for example, of labor tax cuts and transfer payments. Crucially, the compensating reform would fully protect vulnerable households and workers from higher energy prices. ${ }^{51}$

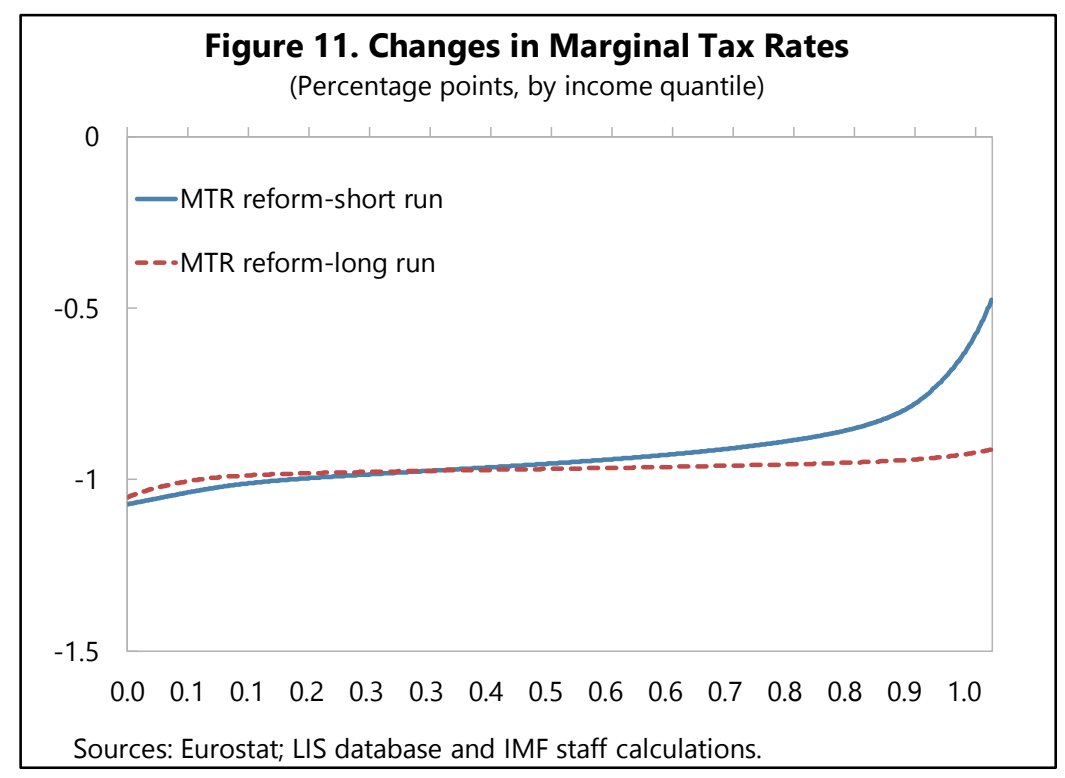

\section{Small reductions in marginal tax rates can compensate households for higher prices} and lower wages due to the carbon tax. In the short run as wage rates respond to changes in labor supply from rigidities in production, the compensating tax reform could be mildly progressive. Marginal tax rate cuts would reach around 1 percentage point for the lowest

\footnotetext{
${ }^{50}$ The burden on households also includes the efficiency loss from the carbon price, approximately one-half the product of the emissions reduction and the carbon price. Given the emission reduction of 20 percent, the size of the efficiency loss is equal to 16 percent of the revenue raised.

51 The specific parameters of the reform will depend on household's real income changes, the elasticities of labor supply and demand and features of the income distribution (Tsyvinski and Werquin 2019).
} 
income workers. ${ }^{52}$ For workers with earnings above the median, the tax rate cuts would be lower and reach around 0.5 percentage points for those at the $99^{\text {th }}$ percentile of the earnings distribution. In the long run (about five years ${ }^{53}$ ) with fixed wages determined by constant returns to labor and capital, the labor income tax reform would reduce marginal tax rates by roughly one percentage point for most workers compared to the current schedule..$^{54}$

\section{Using carbon tax revenues to reduce marginal labor income tax rates would have a positive impact on hours worked and counteract the adverse employment effects of} higher energy prices. In the scenario considered, hours worked decline by around 0.8 percent as the carbon tax is passed forward to higher domestic consumer prices (and therefore lower real returns to work effort) and passed back through lower wages in exporting firms. When the proceeds of the tax are used to reduce marginal tax rates in a way that compensates households for their initial welfare loss, hours worked decline marginally on net in the short-term by an estimated 0.07 percent. In the long run however, they would increase slightly by 0.05 percent.

\section{Other transfer schemes} offer different equityefficiency tradeoffs. The compensating tax reform outlined above can be compared for instance to an alternative transfer policy where the proceeds of the tax are given back lump sum to households. This scheme would further reduce inequality as consumption in the bottom quintile would increase on net by around 2.1 percent on average and decrease by 1.2 percent of consumption for households in the top 20 percent. However, there would be no employment benefits since marginal tax rates would not be reduced. Alternatively, the bottom quintile could be compensated through transfers using 13 percent

\footnotetext{
${ }^{52}$ Essentially all workers face a positive marginal tax rate given that the personal allowance for labor income was only about $\$ 1,500$ in 2015 .

${ }^{53}$ Holmlund and Soderstrom (2011).

54 These simulations assume short run elasticities of labor supply of 0.3 and labor demand of 0.6 . In the long run, the labor supply elasticity is 0.5 while labor demand is assumed to be flat, consistent with constant returns to labor and capital. The current (average) marginal tax rate schedule is estimated by a functional relation using microdata from the Danish Law Model 2016 (see Tsyvinski and Werquin 2019 for details).
} 
of the carbon pricing revenues. This approach however could increase inactivity traps with lower overall labor supply benefits compared with full recycling of carbon tax revenues in marginal tax rate reductions. Several other reforms are possible, for example raising in-work benefits for low-wage workers or reducing the regressive electricity tariff rates to reflect the growing contribution of renewables in production. ${ }^{55}$ Choosing a specific reform will ultimately depend on societies values and preferences over equity and efficiency.

\section{Domestic Mechanisms for Addressing Competitiveness and Leakage}

The European Commission is considering the possibility of an EU-level BCA. A BCA is a charge on embodied carbon in products imported into a jurisdiction with a carbon pricing scheme, perhaps matched by rebates for charges on embodied carbon in exports from the jurisdiction. The BCA could either be an import tax/export subsidy or a requirement for importers to purchase allowances from a domestic ETS with exemptions from the scheme for exporters. Currently concerns about the impact of carbon pricing on the competitiveness of EITE industries (e.g., cement, refining) and leakage ${ }^{56}$ are addressed through granting them free allowance allocations under the EU ETS. But this mechanism will lose viability with deeper decarbonization of industry (see Annex 2) which is one reason for the interest in BCA's. The other reason is that it might induce more carbon pricing in other countries, effectively enabling them to capture the tax base on their emissions. ${ }^{57}$

Carbon leakage can come from changes in global trade patterns. This would occur as higher energy input costs cause domestic firms to lose market shares both domestically and abroad to foreign competitors in jurisdictions without carbon pricing. High domestic carbon prices may then lead to import substitution of emission-intensive goods weakening the impact of unilateral mitigation policies on global emissions. Coordinated policies can limit the extent of leakage because intra-EU trade flows are not affected to the same extent when national carbon price policies are coordinated.

\footnotetext{
${ }^{55}$ Danish Council on Climate Change (2020). The first reform would lower average tax rates for workers and encourage labor force participation but not (as under cuts in marginal tax rates) extra hours worked on the job. Empirical labor supply studies find however that most of the labor supply elasticity is due to the participation response.

${ }^{56}$ That is, the percent of the domestic emissions reductions from carbon mitigation that is offset by increased emissions in other countries.

${ }^{57}$ Only one BCA has been implemented to date, applying to the embodied carbon in imported electricity under California's ETS (see Pauer 2018).
} 
Staff estimates suggest carbon emissions leakage is significant at the EU-level, and considerably more so for small, open economies like Denmark. Wingender and Misch (forthcoming) use sectoral variation in energy prices to recover ex post estimates of carbon leakage. Panel data on the carbon content of trade allows them to look at a broader measure of carbon flows than previous empirical research
Figure 13. Carbon Leakage Rate of National Policies (Share of domestic carbon reduction offset abroad)

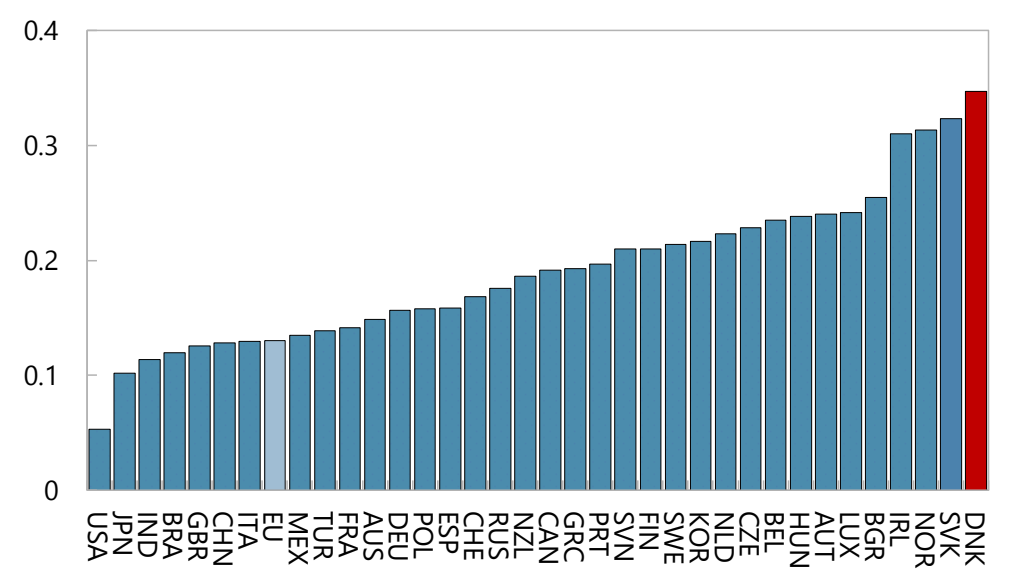

Sources: OECD TECO2 database; Sato, Singer, Dussaux and Lovo 2019; and IMF staff calculations.

that has mainly focused on industry case studies or migration of energy-intensive firms (rather than all firms). The simple average leakage rate from increases in energy prices across the 37 countries and 21 industrial and energy sectors covered in the sample is around 0.2 (Figure 13). It is lowest for some of the largest countries such as the US, China and India and tends to be larger for small open economies. Denmark had the highest leakage rate, at 35 percent (a consequence of high trade openness in embedded carbon) while the leakage rate for the EU is 13 percent. $^{58}$

\section{A feebate may be a more efficient instrument for limiting leakage and competitiveness concerns than free allowance allocation but a BCA could be more efficient still. A} feebate imposes a smaller burden on industries than carbon pricing as there is no transfer payment (i.e., charge for infra-marginal emissions), but it does not promote the entire range of behavioral responses for reducing emissions (Annex 2). Under free allowance allocation the transfer payment is neutralized, but there is a broader cost on the economy as this approach diverts revenue from the general budget, revenue that might have been used to cut marginal tax rates to counteract the harmful employment effects of higher energy prices induced by carbon pricing. Rather than offsetting cost increases for domestic firms, instead a BCA raises costs for imported goods to address competitiveness and leakage effects. Unlike a feebate, it promotes the full range of mitigation responses, and unlike free allowance allocation it does not use up valuable revenues - in fact it raises additional revenue.

\footnotetext{
${ }^{58}$ Danish Economic Council (2019) finds overall carbon leakage rate of around 0.5 percent when including the agricultural sector. Note that leakage can also arise though reductions in international fuel prices (induced by mitigation policies) leading to increased fuel demand in other countries. This second channel would likely be small for a country like Denmark but would potentially be larger for EU-wide mitigation policies. Going forward, both sources of leakage could be reduced if trading partners are meeting binding emissions targets under the Paris Agreement. See Böhringer and others (2012) and Branger and Quirion (2014) for literature reviews on leakage.
} 
There are several key issues to consider in designing a BCA though practical options should be feasible. These issues include (see the summary in Table 3):

- Industry coverage. It would be preferable initially to target EITE industries, since they account for the largest share of trade-embedded carbon, face the highest carbon leakage rates, and their embodied carbon is more reliably estimated than for products with low embodied carbon - embodied carbon in EITE imports was 12 million tons in 2015, or 20 percent of the size of domestic $\mathrm{CO}_{2}$ emissions. ${ }^{59}$ Administrative costs would also be minimized early on as systems and procedures are developed and scaled over time. This narrow BCA would also strengthen the environmental justification of the measure (which could also become important when assessing consistency with trade law rules as discussed below). Consideration should be given to eventually cover all sectors, both other non-energy intensive industry and services which account for 75 percent of embodied carbon in all imports to Denmark. Whether this extension is worthwhile would depend on whether the benefits of additional emissions coverage outweigh the extra administrative burden.

- Country benchmarkfor embodied carbon. The carbon content of individual traded goods is not readily observable. A possible solution could involve the use of trading partners' industry-specific averages, based on internationally recognized methodologies for measuring carbon intensity in industries at the country level. While crude, the use of macro-measures of carbon content ${ }^{60}$ would still serve an important purpose as they could incentivize trading partners to adopt carbon pricing themselves, at least for BCAs in large jurisdictions such as the EU. ${ }^{61}$

- Rebates for domestic exporters. Providing rebates for embodied carbon pricing in exports leaving Denmark would help to address the adverse competitiveness impacts for domestic exporters. At the same time, it also reduces incentives for these producers to reduce their emissions - implying a greater burden of reduction for other domestic emissions sources if a domestic mitigation pledge is to be met-and rebating lowers revenues from domestic carbon pricing. A sequenced implementation might therefore be advisable, with the BCA applying initially only to imports. This

\footnotetext{
${ }^{59}$ From OECD, Trade in Embodied $\mathrm{CO}_{2}$ Database (TECO2). These embodied foreign emissions are not covered by Denmark's 70 percent reduction target, which only includes domestic emissions.

${ }^{60}$ For example, the OECD $\mathrm{TECO}_{2}$ database estimates embodied carbon in imports for EU and advanced countries for 36 sector classifications (ISIC Rev. 4) and by exporting country. But measuring embodied carbon is challenging and there is a need for international collaboration to improve data standards and methodologies. See Sato (2014) for a review of the empirical literature.

${ }^{61}$ See Nordhaus (2015), Böhringer and others (2016).
} 
would also have the advantage of better managing the underlying legal sensitivities associated with granting export rebates/subsidies under trade law rule. ${ }^{62}$

- Revenue use. Revenues from a BCA might be used to lower the likelihood of legal challenges to the BCA. Some of the proceeds could be given back to governments of exporting, developing countries or to finance green development abroad, for instance by channeling the revenues to the Green Climate Fund. Such a transfer mechanism could also be consistent with existing international climate finance obligations (for example, under the Paris Agreement). Nonetheless, most of the burden of a BCA in a small open economy like Denmark would likely be borne by domestic consumers rather than trading partners.

- Adjusting import charges for carbon pricing overseas. In principle, a BCA should ensure equal tax treatment for units of carbon emitted domestically and tradeembedded units that were emitted abroad. A credit should then be given for overseas exporters verifying tax already paid on the embedded carbon.

- Rebating for individual overseas exporters with embodied carbon below their industry average. The use of macro measures of carbon content would not incentivize carbon mitigation for individual foreign producers since the tax would not depend on their own carbon footprint. This could be addressed by adopting a "rebuttable" presumption, meaning importers would be allowed to provide certification from an internationally recognized body that their carbon intensity is lower than the countrysector average. ${ }^{63}$ There is a risk of gaming however, if firms dedicate production from their cleaner plants for export to the BCA area while supplying customers in other countries or at home with production from emissions-intensive plants.

- Differentiating charges by country income. As a general principle, tax law design of BCAs should ideally avoid differentiation of imports by country of origin. However, exceptions could be granted for imports from "least developed countries" (consistent with existing trade law mechanisms). Applying a lower BCA rate for exporters in low income countries would partially undermine the ability of the BCA to address competitiveness and leakage, but it is more equitable. Administrative complexities might be limited through use of a simple formula: for example, a 100 percent discount on the BCA for low-income developing countries.

\footnotetext{
${ }^{62}$ This phased approach is also being considered as an option in the context of incorporating BCAs into the EU ETS.

${ }^{63}$ Examples of such certifications include the World Resource Institute/World Business Council on Sustainable Development GHG Protocol or the ISO 14064 standard.
} 
Table 3. Key Design Issues for BCAs: A Summary

\begin{tabular}{|c|c|c|c|}
\hline Design issue & Administrative considerations & Mitigation incentives & Other comments \\
\hline Industry coverage & $\begin{array}{l}\text { Extending coverage to non-EITIs would } \\
\text { increase administrative burdens... }\end{array}$ & $\begin{array}{l}\text {...and provide little addiitonal } \\
\text { mitigation incentives for overseas } \\
\text { exporters due to the low emobodied } \\
\text { carbon in broader product classes. }\end{array}$ & $\begin{array}{l}\text { Full industry coverage would be } \\
\text { consistent with pricing emissions } \\
\text { embodied in domestic consumption } \\
\text { rather than, as in the Paris framework, } \\
\text { emissions released within national } \\
\text { borders. }\end{array}$ \\
\hline $\begin{array}{l}\text { Country benchmark } \\
\text { for embodied carbon }\end{array}$ & $\begin{array}{l}\text { Measuring embodied carbon according } \\
\text { to the overseas exporting country } \\
\text { (rather than domestic industry) } \\
\text { complicates administration... }\end{array}$ & $\begin{array}{l}\text {...but provides incentives for } \\
\text { governments of overseas exporting } \\
\text { countries to strengthen mitigation } \\
\text { policy. }\end{array}$ & $\begin{array}{l}\text { Measures of embodied carbon at the } \\
\text { industry level are publicly available for } \\
\text { most countries. }\end{array}$ \\
\hline $\begin{array}{l}\text { Rebating domestic } \\
\text { exporters }\end{array}$ & Modest administrative burden. & $\begin{array}{l}\text { Removes mitigation incentives for } \\
\text { domestic exporters (which moderately } \\
\text { offsets efforts to meet Paris pedges for } \\
\text { domestic emissions). }\end{array}$ & $\begin{array}{l}\text { Modestly reduces revenue from } \\
\text { domestic carbon pricing. }\end{array}$ \\
\hline Revenue use & $\begin{array}{l}\text { Alternative revenue uses have little } \\
\text { implication for administrative burdens. }\end{array}$ & $\begin{array}{l}\text { Using revenues for domestic green } \\
\text { investment or international climate } \\
\text { finance would enhance mitigation. }\end{array}$ & $\begin{array}{l}\text { Using some revenue for international } \\
\text { climate finance/rebates to overseas } \\
\text { governments could help with CBDR-CR } \\
\text { and lower risk of retaliation/WTO } \\
\text { ruling BCA is a protectionist measure. }\end{array}$ \\
\hline $\begin{array}{l}\text { Adjusting import } \\
\text { charge for carbon } \\
\text { pricing overseas }\end{array}$ & $\begin{array}{l}\text { Modest administrative burden (though } \\
\text { procedures may be needed to detect } \\
\text { re-labelling pre-eixting fuel taxes as } \\
\text { carbon pricing). }\end{array}$ & $\begin{array}{l}\text { Incentive for governments in exporting } \\
\text { country to increase carbon pricing--not } \\
\text { least, this enables them to capture the } \\
\text { tax base on their own emissions. }\end{array}$ & $\begin{array}{l}\text { For competitiveness considerations, } \\
\text { overseas pricing needs to cover power } \\
\text { generation/industry. For promoting } \\
\text { effective carbon pricing it should also } \\
\text { cover transport/buildings. }\end{array}$ \\
\hline $\begin{array}{l}\text { Rebating for } \\
\text { individual overseas } \\
\text { exporters with } \\
\text { embodied carbon } \\
\text { below their industry } \\
\text { average }\end{array}$ & $\begin{array}{l}\text { Modest administrative burden. Onus } \\
\text { would be on overseas firms to } \\
\text { demonstrate lower embodied carbon. }\end{array}$ & $\begin{array}{l}\text { Provides mitigation incentives for } \\
\text { individual exporters. But may also } \\
\text { cause shifting of sales from emissions } \\
\text { intensive firms/plants to countires } \\
\text { without pricing. }\end{array}$ & $\begin{array}{l}\text { Third party data sources might validate } \\
\text { embodied carbon at firm/plant level. }\end{array}$ \\
\hline $\begin{array}{l}\text { Differentiating } \\
\text { charges by country } \\
\text { income }\end{array}$ & $\begin{array}{l}\text { Modest additional administrative } \\
\text { burden. }\end{array}$ & $\begin{array}{l}\text { Lowers penalty for insufficient pricing } \\
\text { in non-advanced countries but more } \\
\text { consistent with CBDR-RC principle. }\end{array}$ & $\begin{array}{l}\text { Only partially addresses } \\
\text { competitiveness/leakage. But may } \\
\text { lower risk of trade retaliation, or even } \\
\text { withdrawal from Paris Agreement, by } \\
\text { non-advanced countries. }\end{array}$ \\
\hline
\end{tabular}

Legal aspects surrounding a BCA for Denmark are uncertain. A legal analysis is beyond the scope of this paper, but a few key principles are particularly relevant:

- While EU trade law guarantees free trade among member countries, the application of a charge on imports between EU countries would not be without precedent. Value added taxes are applied on within-EU imports and member states can apply different VAT rates to imports from outside the union. Importantly, the economic equivalence between a domestic carbon tax with BCA and the taxation of carbon consumption is broadly understood in the literature. ${ }^{64}$ Still, economic equivalence is distinct from

${ }^{64}$ See for instance Böhringer and others (2017). 
legal equivalence for trade law purposes, which is yet to be determined. ${ }^{65}$ It remains an open question whether the EU would hinder efforts by a member state to decarbonize faster using more effective tools in support of ambitious domestic policies. The current broad political agreement on the importance of combatting climate change suggests perhaps a Danish BCA would be a welcome innovation to be emulated at the EU level.

- WTO consistency requires equal treatment between domestic and foreign "like" products. This would be supported by the use of detailed and accurate data on embodied carbon of products. International collaboration on data, standards and methodologies would help improve the accuracy and effectiveness of BCAs. Equivalent treatment would also require crediting carbon pricing abroad on products and their inputs so that the effective burden is the same for domestic and foreign producers. This could incentivize partner countries to improve transparency in their domestic carbon pricing policies.

- $\quad$ Finally, replacing existing measures to address the competitiveness of domestic firms (e.g. free quota allocations in the EU-ETS, exemptions) facing high carbon prices would support the view that BCAs are used for environmental purposes instead of as protectionist measures.

\title{
V. Mitigation Policies for Agriculture, Fisheries And Forestry
}

\begin{abstract}
On account of its arable landscape, Denmark has for long been a predominantly agricultural country. However, since the end of WWII, Denmark has diversified significantly out of agriculture. Over time, the sector has also evolved reflecting technological innovation, and despite its relatively small size, Denmark to date produces three times the food it needs to feed its population and, as a result of this, it is the only country in the Nordic-Baltic region that is a net exporter of food, in addition to oil and natural gas.
\end{abstract}

\section{Food production and exports comprise predominantly meat and meat products, dairy products, and fish — all products, like fossil fuels, with significant environmental impact. Within the EU, Denmark exhibits the second highest share (64\%) of animal output in total agricultural output after Ireland (75\%). In particular, Denmark is a leading producer of pork globally, the largest exporter of pork products in the EU (see Box 1) and a global}

\footnotetext{
${ }^{65}$ WTO rules (which generally look to legal form of relevant measures) in general permit border adjustments on "indirect" taxes only. Given the stronger link between carbon taxes with BCA and a firm's underlying production activities, it is not necessarily the case that all BCAs would be accepted as being legally equivalent to "indirect" taxes. According to the WTO's Agreement on Subsidies and Countervailing Measures (SCM Agreement), these are defined as "sales, excise, turnover, value added, franchise, stamp, transfer, inventory and equipment taxes, border taxes and all taxes other than direct taxes and import charges."
} 
leading exporter of fish both wild caught and farmed commercially. Two Danish territoriesGreenland and the Faroe Islands - engage yearly in the hunt of hundreds of whales mostly for domestic consumption, making Denmark one of the top whaling nations in the world alongside Japan and Norway. Finally, fur farming is Denmark's third largest type of animal farming. This makes Denmark the largest producer of mink skins in the world, together with a small number of fox, chinchilla and rabbit skins, producing 40 percent of the world's pelts, which ranks third in Denmark's agricultural export items of animal origin.

The role of animal farming in the country's production, and major share of industrial feed crops for forage, makes the agriculture, fishery and forestry (AFOLU) sector an above-average contributor to the country's total GHG emissions relative to peers. According to Eurostat data, Denmark's share of GHGs from crop and animal agriculture in total GHGs in 2019 was over double the average in other EU countries, ${ }^{66}$ and emissions from food waste remain significant (see Box 1). These figures do not include emissions from whaling activities and are susceptible to assumptions made in calculating livestock emissions.

The government recognizes that a successful emissions mitigation strategy must include measures to reduce emissions from farming. In its newly released report detailing planned contributions by sector for 70 percent carbon mitigation by 2030, the government announced plans to cut emissions from agriculture and forestry by about 4-5 million tons of $\mathrm{CO}_{2}$-eq (equivalent to 8 percent of total 2018 emissions) over the next ten years although these estimates are subject - according to the report - to "very large uncertainty in relation to the ultimate effectiveness of advocated mitigation methods" (see Klimaprogram, 2020, page 23 last bullet). ${ }^{67}$ The report indicates that this target would be attained by focusing on the development of new technologies and solutions that can reduce the climate and environmental impact of food production and agriculture, including through new feed additives, better slurry management and biorefining. More initiatives may be announced when the government spells out further its sector strategy for agriculture in coming months.

Recent plans add to ongoing greening policies in this area, reaffirming the government commitment at home and abroad to make agriculture and forestry more sustainable. Working at the European level, the government has pushed for a pan-European reduction

\footnotetext{
${ }^{66}$ In 2018, the share in Denmark was 22 percent versus 10 percent in other EU countries. See Eurostat (2020). Total emissions include all sectors and indirect $\mathrm{CO}_{2}$ (excluding emissions from land use resulting from direct human-induced land use such as settlements and commercial uses, land use change and forestry activities, i.e. 'LULUCF', emissions from post-production waste of food and crop, and memo items). Greenhouse gases include $\mathrm{CO}_{2}, \mathrm{~N} 2 \mathrm{O}$ in $\mathrm{CO}_{2}$ equivalent, $\mathrm{CH}_{4}$ in $\mathrm{CO}_{2}$ equivalent, $\mathrm{HFC}$ in $\mathrm{CO}_{2}$ equivalent, $\mathrm{PFC}$ in $\mathrm{CO}_{2}$ equivalent, $\mathrm{SF}_{6}$ in $\mathrm{CO}_{2}$ equivalent, $\mathrm{NF}_{3}$ in $\mathrm{CO}_{2}$ equivalent).

${ }^{67}$ Increased fat content in feed for conventional dairy cows and heifers (-); Frequent slurry of manure in pig houses (-) Increased and further afforestation; nitrogen targets.
} 
commitment and strengthened regulation of agriculture, working to ensure that the EU agricultural reform is used to support common climate roofs with a view to reducing greenhouse gas emissions in agriculture.

\section{At home, in 2015, the Danish government announced an ambitious new strategy to double organic farming by 2020 (relative to 2007). ${ }^{68}$ The plan includes serving more} organic food in the nation's public institutions, requiring organic farming on public lands, subsidies for farmers transitioning to organic, and simplifying organic regulations. As a result of the plan, by 2019, about 10 percent of land reserved for agriculture in Denmark has been transformed into organic land, and the number of organic farmers in the country is now close to 4,000 . Nearly 8 percent of all food sold in Denmark is organic, the highest percentage in Europe and Danish organic export has risen by more than 200 percent since $2007 .{ }^{69}$

\section{The government has taken parallel steps in regulating the domestic fish industry. In} 2019, Denmark declared that with the number of its active fish farms the country had reached the limit of fish it can farm at sea without harming the aquatic environment - citing ongoing challenges with oxygen deficiencies, risks of biodiversity loss and stubbornly high levels of nitrogen emissions from the open-water fish farms and hatcheries, despite significant industrial efforts over the years to make the business sustainable. As a result, the government blocked further development of new aquaculture projects at sea. ${ }^{70}$ The government is also a member of the International Whaling Commissions and abides to its yearly whale catches quota allocations.

\footnotetext{
${ }^{68}$ Batini and Pointereau (forthcoming). The government's Ministry of Food, Agriculture and Fisheries' 67-point plan, dubbed "Økologiplan" focuses heavily on a more organic public sector and aims to strengthen cooperation between municipalities, regions and ministries to speed up the transition from conventional to organic production on publicly owned land with a long line of new initiatives to strengthen both development and conversion working with alternative ownership and operation models.

${ }^{69}$ Batini and Pointereau (forthcoming).

${ }^{70}$ Even after the outbreak of coronavirus cases registered in 2020 in various mink farms, unlike the Netherlands, Denmark has not passed legislation aimed at closing its massive mink sector, but it did begin to phase out its fox fur market in 2009 (with plans to phase it out completely by 2023). Several EU countries have ended their fur farm industries in recent years, often in response to animal welfare concerns. Austria, Belgium, Luxembourg, Slovenia, Croatia, Czech Republic, Slovakia, and the United Kingdom have banned fur farming, and Ireland is in the process of passing a ban on fur production. Legislative proposals to end fur farming have recently been introduced in Bulgaria and Lithuania.
} 


\section{Box 1. Sources of Agricultural GHG Emissions in Denmark}

These emissions reflect three main factors:

- Most crop production focuses on a few crops and utilizes synthetic fertilizers and pesticides (practices with high environmental impacts). ${ }^{1}$ Around 80 percent of Denmark's grain and plant production is utilized as feedstuff in animal production.

- Animal farming is highly industrialized (livestock density per utilized agricultural area in Denmark is more than double the EU-27 average) and focused on cattle and pigs which have increased rapidly in the last decade and are emissions intensive (Willett and others 2019, IPCC 2019). Cows release methane (a potent GHG) through enteric fermentation, as do pigs (albeit in smaller proportions), while management of their waste produces large amounts of nitrous oxide. ${ }^{2}$ In 2018 , the total number of cattle and pigs in Denmark exceeded 1.5 million and 28 million respectively (five pigs for every Danish citizen), while the stock of sheep, by contrast, is around 0.2 million. ${ }^{3}$ Denmark is also a top breeder of mink for the fur industry with over 3 million animals raised yearly.

- Food waste, albeit more limited per capita than elsewhere in the EU, also contributes to GHG emissions. About 0.2 million tons of food, with a value of $\$ 2.7$ billion, and more than 2.2 million tons of $\mathrm{CO}_{2}$ equivalent ( 6 percent of Denmark's total) is wasted or lost a year. ${ }^{4}$

${ }^{1}$ For example, the chemical input of nitrogen as fertilizer, an important source of GHGs and soil degradation, is considerably higher in Denmark than in the EU on average (Eurostat, 2020). More specifically, the nitrogen (N) fertilizer consumption per hectare of fertilized utilized agricultural area (UAA) in the Denmark in 2017 corresponded to $98.2 \mathrm{~kg} / \mathrm{ha} \mathrm{vs} .75 .9 \mathrm{~kg} / \mathrm{ha}$ in the EU-28. https://ec.europa.eu/eurostat/statistics-explained/index.php?title=Agri-environmental indicator mineral_fertiliser_consumption\#Analysis_at_EU level.

${ }^{2}$ Batini (2019), Batini and Pointereau (forthcoming). Methane and nitrous oxide have Global Warming Potential (GWP) of 28-36 and 265-298 that of carbon dioxide respectively, over a 100-year timescale. And much higher still over a shorter timespan implying immediate reductions in Denmark's contributions to global warming, contrary to cuts to the use of fossil fuels which has a more delayed impact on global warming given the phenomenon of "committed warming" (Batini and Pointereau, forthcoming).

${ }^{3}$ Danish Agriculture and Food Council (2019).

${ }^{4}$ EU Fusions (2016).

Big steps, finally, have been made to reduce food loss and waste which is a key contributor to GHG emissions. Denmark has been hailed the European champion of food waste reduction. Between 2011 and 2017 food wasted dropped by 25 percent thanks to an aggressive campaign by "Stop Wasting Food" - an NGO backed by the Danish government that promotes capillary retail and consumer policies to avoid food loss.

\section{More could be done however to reduce GHGs emissions from animal agriculture and}

fishing. Livestock - through a combination of enteric fermentation, manure storage and feed production - is the number one contributor to GHG emissions in the agricultural sector globally (FAO, 2017), with beef and dairy cattle responsible for the most emissions, on a commodity basis, followed by pig meat (IPCC, 2019; Harwatt et al., 2020. See Figure 14). Given Denmark's large herds of cattle and pigs, it follows that managing emissions from livestock offers an 
important lever to reduce the sector's contribution to climate change. In addition, a strategy to protect whales and increase their populations can be effective at reducing greenhouse gases since marine biologists have recently discovered that whales - especially the Great whales such as those hunted by Denmark - play a significant role in capturing carbon from the atmosphere (Lutz et al., 2014; Roman et al., 2014; Chami et al., 2019; Chami et al., 2020).

\section{For livestock emissions on land, mitigation may occur directly by reducing the amount of greenhouse gases emitted, or indirectly through the improvement of production efficiency.} A recent report by the Danish Council on Climate Change, backing current government plans, suggests a mitigation strategy for livestock emissions based primarily on improvements in the way livestock is managed given existing herds (Danish Council on Climate Change, 2020). Specifically, the Council suggested cutting emissions by improving the way farmers handle liquid manure ('slurry,' which is a source of both methane and nitrous oxide, two very potent GHGs) and by feeding dairy cattle additives proven to reduce the gas released through enteric fermentation. Recent research, including by the European Commission's Joint Research Centre and by researchers at Aarhus University, comparing methods to reduce emissions from livestock shows however that the potential mitigating effect of improved livestock management methods like the ones suggested by the Council are small and highly uncertain (see Leip et al., 2019; Grossi et al., 2019; and Petersen, 2018). ${ }^{71}$ This tallies with analysis by gold-standard estimates the IPCC on land use indicating that mitigation gains from improved livestock management are moderate in a medium confidence scenario (IPCC, 2019). In addition, the most effective feed additives to reduce enteric fermentation, for example from special types of seaweeds, are not abundant in the wild and would have to be farmed especially at sea in great quantities, making this solution challenging given Denmark's ambitious overall emissions abatement timetable.

\footnotetext{
${ }^{71}$ Indeed, the Council estimates only modest gains from feed additives for example, based on newest data from Aarhus University indicating that enteric methane emissions from cattle can be reduced by a mere 8 percent by adding more fat from rapeseed to the fodder. See https://klimaraadet.dk/da/rapporter/kendte-veje-og-nye-spor-til-70procents-reduktion. Bovaer, for example, is a feed additive containing rapeseed oil, that could potentially reduce methane emissions by up to $1 / 3$, likely less, but its ultimate impact is highly uncertain, and the drug is not on the market yet pending EU approval expected for 2021.Similarly, the Council proposal of "better slurry management," that involves a combination of increased acidification where this is the preferred option, gasification, cooling and rapid removal of slurry from the barn, is not estimated to lead to significant mitigation. For more details see https://klimaraadet.dk/da/rapporter/kendte-veje-og-nye-spor-til-70-procents-reduktion.
} 
A more effective mitigation strategy relies in significantly reducing the number of animals farmed. Science-driven, time-bound global mitigation plans to deliver commitments-including Denmark's - under the Paris Climate Agreement show that a halving of GHG emissions across the board is needed by 2030 to keep global temperatures within $1.5^{\circ} \mathrm{C}$ by 2050 (Röckstrom et al. 2017; see also Harwatt et al. 2020). Accordingly, reducing the size of Danish livestock gradually by 2030, for example by a half, can directly and predictably cut down emissions by an amount compatible with Denmark's domestic and international mitigation commitments, while maximizing the certainty of attaining zero-carbon goals within the prescribed horizon. Specifically, based on staff estimates of livestock emissions in Denmark of cattle and pig alone, calculated using life-cycle assessment models (LCA) estimates by the FAO, by breeding half the number of cattle

Figure 14: Total Estimated GHG Emissions in Denmark by type of animal ( 2018 heads)

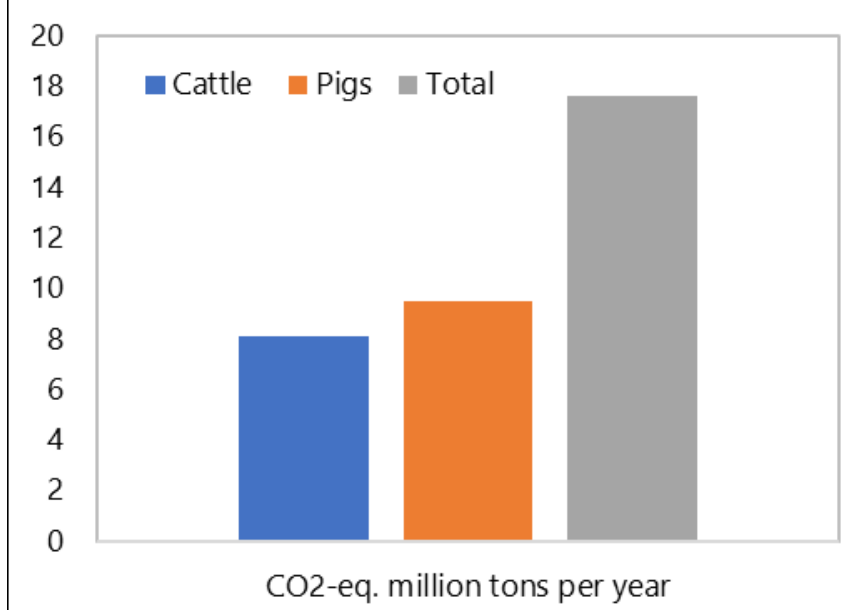

Source: IMF staff calculations based on Eurostat, Darlgaard, 2007; Kool et al., 2009; McLeod et al., 2013; and Opio et al., 2013. and pig it breeds today, Denmark could eliminate over 17 percent of its 2018 total GHG emissions' balance..$^{72}$ These reduction targets include livestock that is raised for export since most of the life carbon/methane/nitrous oxide/nitrogen cycle of exported animals takes place in the country of origin since upon import livestock is typically transported directly to a slaughtering facility. During and beyond the transition to smaller herds, livestock management improvements like the ones suggested by the Danish Council and planned by the government can help curb emissions further at the margin.

A bold reduction in Danish livestock would allow to reduce the need to devote most arable land to industrial feedstuff monocrops (see Box 1) cutting emissions further as demonstrated in model analysis for EU countries with similar livestock configurations (see, for example, Solagro, 2016). This would allow to expand upon Denmark's successful path towards a gradual conversion to organic farming (or spare the conversion of more land with high-storage capacity

\footnotetext{
${ }^{72}$ Calculations in Figure 14 assumed that beef emits $14.7 \mathrm{~kg} \mathrm{CO} 2-\mathrm{eq} / \mathrm{kg} \mathrm{CW}$ and pigs between $3.55-4.74 \mathrm{~kg} \mathrm{CO} 2$ eq $/ \mathrm{kg} \mathrm{CW}$ where CW stands for 'carcass weight' based on hot carcass weight values (HCW) These figures reflect standard estimates in McLeod et al., (2013) and Opio et al. (2013) and capture all GHG emissions from enteric fermentation, manure management and feed crops. The estimates have been averaged with estimates by Kool et al., 2009 and Darlgaard (2007) using Data from Danish farms. It is also assumed that each beef carcass weighs on average $363 \mathrm{kgs}$ and each pig carcass weighs $80 \mathrm{kgs}$. These are conservative estimates. Latest data on cattle and pig populations in Denmark are 2018 and taken from Eurostat. These estimates seem to suggest that emission from livestock in Denmark may be higher than what currently reported by Eurostat for 2018 for comparable GHGs in $\mathrm{CO}_{2}$-eq metrics ( 6.63 million tons of $\mathrm{CO} 2$ eq.), implying that total emissions excluding land use, land use change and forestry (LULUCF) may be also proportionally higher than what reported by Eurostat for 2018.
} 
for carbon like peatlands from farming) which actually helps sequester carbon into the soil over the medium to long run as opposed to just mitigating it (Lal, 2004; He et al., 2016; Danish Council on Climate Change, 2020) and putting at least some livestock on pasture, a way to reduce GHG emissions through enteric fermentation naturally. When grazing land is not required or is unsuitable for arable production, land could be repurposed as a carbon sink by restoring native vegetation cover to its maximum carbon sequestration potential, like peatland, as suggested in Harwatt et al. (2020). Co-targets could be announced on organically farmed land and carbon-sink-purposed land alongside targets for the reduction of the number of the country's top-emitting animals. This strategy is compatible with the European Green Deal and efforts under the EU's Farm to Fork Strategy to make European food systems fair, healthy and environmentally friendly and reduce the use of pesticides, antibiotics and fertilizers dramatically by 2030 while improving animal welfare. ${ }^{73}$

Studies indicate that to attain mitigation goals, reduced emissions intensity needs to be coupled with commensurate changes in consumption patterns and overall reduced per-capita consumption of livestock products, especially red meat and dairy products (Bajželj, et al, 2014; van de Kamp et al., 2018; Willett et al. 2019)..$^{74}$ Denmark is one of the world's top consumers of meat per capita. Since the consumption of animal food is strongly engrained in Denmark's cultural and heritage tradition, this implies significant and coordinated policy efforts to manage both behavioral changes on the side of consumers and to incentivize and manage structural change in the agri-food supply chain. The Danish Council for Climate Change concurs with this general principle, discussing the need to act on reducing the consumption of high externality foods, notably meat and dairy, in its 2020 report (The Danish council for Climate Change, 2020).

\section{A parallel reduction in the supply and demand of meat would ensure that GHGs currently} produced in Danish farms do not "leak" abroad either through import or export substitution. A strategy that reduces the consumption of animal food in Denmark, in line with nutritional guidelines by the WHO and recent science on health-sustainable diets, would ensure that lower production of animal food in Denmark is not met with greater imports of animal food, risking to leave the global carbon balance unchanged (WHO, 2020; Willett et al., 2019). At the same time, lower production of animal food in Denmark can help validate policies in countries currently importing Danish animal food and that are on the path of making their population's diets healthier and more sustainable.

\section{Additional environmental and public health gains can be generated beyond mitigation by adopting a strategy involving a gradual shift to smaller herds and more extensive (on}

\footnotetext{
73 The EU recently launched "Farm to Fork" strategic envisages a halving of both pesticides and antibiotics in use in EU farms by 2030 , plus a $1 / 5$ cut in fertilizers and an increase of organically-farmed land by 25 percent in the EU on average plus changes to animal welfare legislation both on land and at sea. See https:/ec.europa.eu/food/sites/food/files/safety/docs/f2f_action-plan_2020_strategy-info_en.pdf.

${ }^{74}$ Red meat includes beef, goat, lamb, mutton, pork and venison.
} 
pasture) animal farming. ${ }^{75}$ Intensive animal farming of the type practiced in Denmark and consuming a diet rich in animal food have been associated with important public health risks. These include risks from:

- Zoonotic diseases. Denmark's animal farming is based predominantly on industrial animal farming methods. These industrial-scale facilities, more commonly known as "factory farms," where thousands of genetically similar animals are packed together in overcrowded quarters and are vulnerable to disease due to the stress placed on their immune systems by these living conditions, pose pandemic risks because they have been shown to breed lethal bacteria as well as an array of flu viruses, like the bird (poultry) 2006 HPAI (highly pathogenic avian influenza) or the swine 2009 H1N1 flu. Research shows that like "wet" markets in Asia, Africa and South America, these farms create the perfect conditions for rapid amplification and spread of pathogens (Saenz et al., 2006). Similarly, fur farms, like Denmark's, where thousands of the animals may be crammed together in rows of wire cages, are also a potential source and site for the spread of lethal viruses depending on the stringency of biosecurity regulation in place. ${ }^{76}$ In 2020 , for example, coronavirus spread to several mink farms in Europe leading some countries to ban fur farming. In November, the government announced that 17 million minks across 1,000 farms are to be culled in Denmark as well, after a mutated version of the coronavirus that can spread to humans was detected on Danish mink farms, posing a risk to the effectiveness of a future Covid-19 vaccine globally.

- Antimicrobial resistance. Typically, industrial animal farms make use of subtherapeutic doses of antibiotics in feed to prevent infections caused by the overcrowding of animals and artificially foster weight gain. While this lowers the price of meat, it also means antibiotics may no longer be effective when we really need them (Martin, Totthatil and Newman, 2015; WHO, 2015; O’Neill et al. 2016). While Denmark deserves credit for its antimicrobial stewardship and for advancing farming practices to raise antibiotic-free pigs, risks of antimicrobial resistance would be reduced considerably more if more progress was made to extend these practices, which in 2018 interested only 0.7 percent of the countries' pig population). Industry officials in Denmark say they hope to raise 1.5 million pigs completely free of antibiotics by 2023, up from 200,000 in 2018 bringing the percentage of antibiotic-free pigs, however, to a mere 5 percent of the total. A shift to more natural living conditions achieved by reducing herd population and thus pivoting farming methods away from intensive toward extensive farming can help

\footnotetext{
${ }^{75}$ Contrary to other parts of the world, livestock emissions in Western Europe from grassland systems (extensive) are similar to emissions from industrial systems (intensive) so a shift from the latter to the former would not erode gains obtained by shrinking the size of herds bred. See FAO's GLEAM 2.0 (2017).

${ }^{76}$ Government-led research in the Netherlands suggested mink farms were the first known site of likely animal-tohuman coronavirus transmission. See: https://www.government.nl/latest/news/2020/05/19/new-results-fromresearch-into-covid-19-on-mink-farms.
} 
advance fast on to the path of antibiotic-free animal farming in line with recent guidelines on the use of antibiotics in animal agriculture by the World Health Organization. ${ }^{77}$

- Non-communicable diseases. Research shows that balanced diets, featuring plantbased foods, such as those based on coarse grains, legumes, fruits and vegetables, nuts and seeds, and animal-sourced food produced in resilient, sustainable and low-GHG emission systems, generate significant co-benefits in terms of human health in addition to present major opportunities for adaptation and mitigation (IPCC, 2019; Willett et al., 2019). By contrast, risks of certain Figure 15: Avoidable mortality (preventable and treatable) and health expenditure

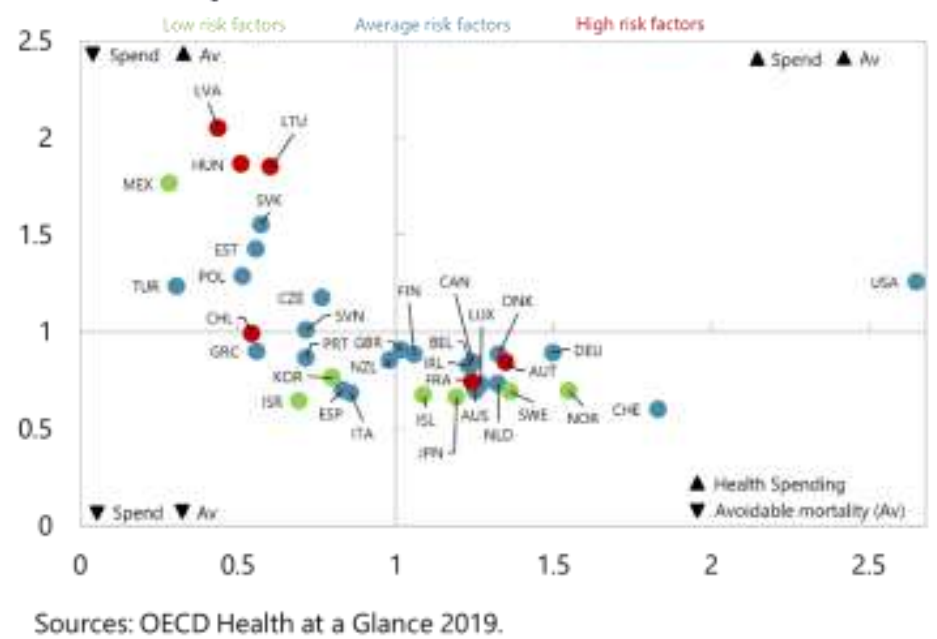
cancers, diabetes Type II, obesity and cardiovascular diseases have been shown to increase with the consumption of processed and red meat products (Willett et al., 2019). Making diets healthier is particularly relevant for Denmark, a high-spending country on healthcare among advanced economy peers that however exhibits lower outcomes in terms of avoidable mortality on grounds of higher rates of obesity, cancer and strokesomething which has been ascribed to Denmark's nonmedical determinants of health, such as a poor diet, as shown in earlier Fund analysis (e.g. in the AIV Staff Report for the 2013 consultation. See Figure 15).

- Air and water pollution. Both industrial crop and animal agriculture and aquaculture are responsible for the vast majority of air and water pollution globally. Negative human health effects from livestock can arise as respiratory disease from air pollutants, especially ammonia, originating in the leakage of nutrients into the atmosphere and water from the animals and their manure; while both nitrogen and phosphorous (together with other pollutants from animal farming like antibiotics and hormones) from fertilizers leaches through soils into water courses and eventually into lakes, seas and oceans causing severe environmental damages (like eutrophication). A shift to lower livestock populations can help improve Danish air and water on land and at sea, and can help Denmark comply with

\footnotetext{
${ }^{77}$ WHO recommends that farmers and the food industry stop using antibiotics routinely to promote growth and prevent disease in healthy animals. See https:/www.who.int/foodsafety/areas_work/antimicrobialresistance/cia_guidelines/en/.
} 
the EUs revised National Emissions Ceilings Directive targeting reductions in ammonia $\left(\mathrm{NH}_{3}\right)$ and non-methane volatile organic compounds (NMVOCs), in addition to nitrogen oxides (NOx), sulphur dioxide $\left(\mathrm{SO}_{2}\right)$ and fine particulate matter (PM2.5).78

Protecting whales offers an additional, "no-tech" nature-based solution to climate change. Whales store tens of tons of carbon in their bodies and sequester it permanently when they die and sink to the bottom of the sea but release that carbon into the atmosphere if they are taken out of the water. In addition, they have a multiplier effect of increasing the production of phytoplankton - which globally contributes to at least 50 percent of all oxygen in the Earth's atmosphere by capturing an estimated 40 percent of all CO2 produced (Pershing et al., 2010; Chami et al., 2019; and Chami et al., 2020). Letting whales live can thus have immediate, highimpact effects on global temperatures: globally, even a 1 percent rise in phytoplankton productivity from whale activity would correspond to the sudden appearance of 120 billion mature trees over the typical lifespan of a whale (Chami et al., 2019 and Chami et al., 2020). ${ }^{79}$ Beyond GHG sequestration, healthy whale populations ensure a healthy marine ecosystem that recycles nutrients between oceans and land. These benefits accrue in large part to the countries bordering the marine areas where they are hunted because cetaceans tend to follow routine patterns of seasonal migration and thus tend to gravitate in certain marine areas most of their lives (see, among others, Safina, 2020).

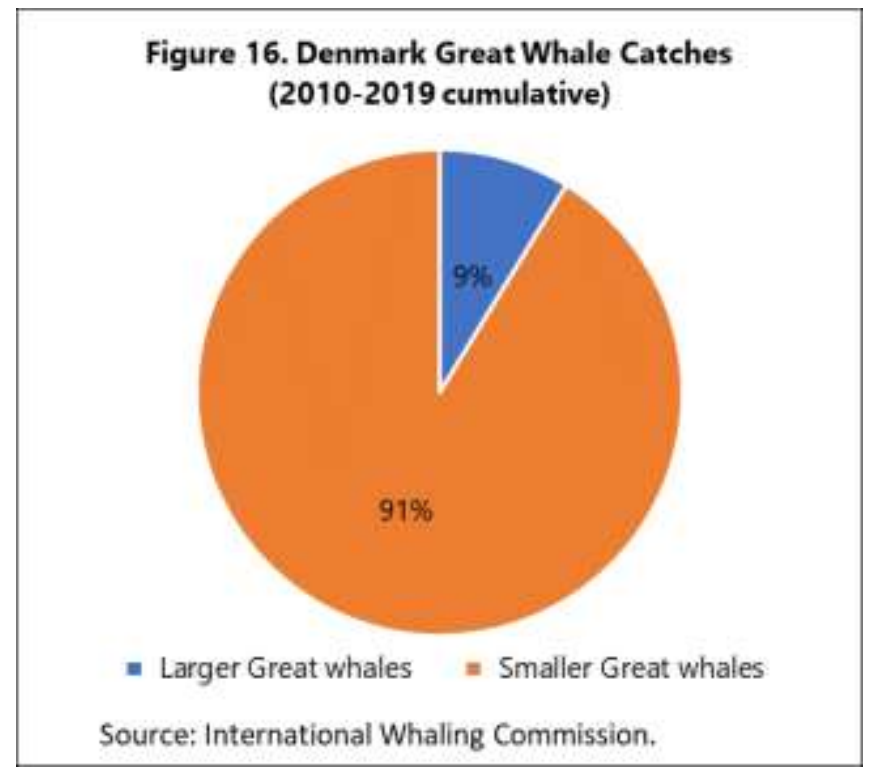

Whales are especially vulnerable to vessel strikes and naval acoustic pollution because their habitat and migration routes are close to major ports and often overlap with shipping lanes, making Denmark—the world's fifth largest shipping nation-a key player in the

\footnotetext{
${ }^{78}$ Air pollution has received less attention than it merits in agricultural debates. Yet it is considered the largest environmental health risk in the EU and it is estimated that one in four Europeans will die or fall sick due to air pollution during their lifetime (WHO Regional Office for Europe and OECD, 2015).

${ }^{79}$ Under standard assumptions about sex ratios and fertility and mortality rates, considering a logistic population growth rule, the kill of one fertile Great whale female specimen in a given year can lead to the potential loss of around 70-80 new specimens over thirty years, as her female offspring, in turn, reach sexual maturity and start giving birth during that period. Great whales leave on average 90 years and calve every 1-3 years under favorable conditions, beginning at around 7-10 years of age, all depending on the species (Safina, 2020).
} 
international effort to understand and reduce the threat posed to them by ship strikes. Beyond accidental kills, two Danish territories - Greenland and the Faroe Islands - rely heavily on the health of both land and marine ecosystems for many of their economic activities and exports but have historically engaged in indigenous whaling of larger Great whales (Figure 16). While these two territories decide their climate targets independently from Denmark, setting an ambitious strategy for the protection of cetaceans at the national level and exploring ways to seek the cooperation of those territories within that overarching strategy may be both more appropriate and more effective given that biodiversity targets as well as nature-based solutions to climate change are centrally discussed at the level of nation states (see for example Mansoura et al. 2020).

\section{Increasing organic production can help sequester more carbon and thus net off current} emissions, over the medium term, but has immediate positive effects on biological diversity, air, soil and water pollution, and public health. Extending government plans to double or triple the amount of land currently farmed by 2030, in tune with EU targets contemplated in the context of EU's new "Farm to Fork" strategy, offers another important lever for climate change mitigation because organically-farmed soil can store vast amounts of carbon over time, while industrially-farmed soils oozes carbon into the air (Lal, 2009; Hauken, 2017; Project Drawdown, 2020). This measure would help cut down current emissions from land use, complementing the proposal by the Danish Council on Climate Change to stop clearing pristine land (like peatland) to curb emission trends from land use change (Danish Council on Climate Change 2020).

Fiscal policy has a central role in promoting a shift from intensive animal agriculture to more sustainable, safer methods as well as natural climate change solutions, and nudging consumers into dietary changes that are both sustainable and healthy. Proxy emissions fees or feebates at the farm level (using farm-level data) can be levied to steer production toward notional emissions targets using calibrations based on: ${ }^{80}$

- The type of animal bred (lowering the fiscal burden on operations involving more sustainable animals like poultry, while raising fees/taxes or setting feebates at zero for operations involving cattle and pigs);

- The way animals are bred (lowering the fiscal burden on operations involving animals raised on pasture at lower densities, compared with confined animal feeding operations using forage produced through embodied deforestation or intensive monocrops);

\footnotetext{
${ }^{80}$ This proposal is similar in spirit to earlier proposals by the Danish Council (Danish Council on Climate Change, 2016) also involving a (proxy) carbon tax at the farm level based on number of livestock, fertilizer use, feedstock, etc.
} 
- The type of crops farmed (lowering the fiscal burden on farms producing leguminous, pulses and cereals for human consumption while increasing it for farms engaged in the production of less sustainable produces, like animal forage);

- The type of farming method (lowering the fiscal burden on organic farms relative to industrial/conventional and integrated farms); and

- Farm size (lowering the fiscal burden for smaller, polyculture farming activities or farms with a relatively high labor-to-acre ratio relative to large, monoculture, and highly mechanized farms).

- Land use beyond farming. Reconverted land during the transition that ends up no longer being used for grazing, horticulture or crops could receive subsidies for carbon sequestration based on sequestration services and reconversion costs.

On the demand side, a (Pigouvian) tax could be applied to foods (notably meat and dairy) associated with high negative environmental externalities. This tax would be, calibrated to the elasticity of Danish-specific demand and the desired quantity equilibrium for these foods, along the lines of what Simon (2013) proposed for the United States. The Danish Council of Climate Change suggests a target of 13 krona per kilo of ground beef and 2 krona for liter of milk-implying an approximate tax of about 21-30 percent for ground beef and about 20 percent for milk at current prices - targeting a considerably smaller reduction ( 2 million ton) in $\mathrm{CO}_{2}$-eq emissions from meat and dairy consumption domestically (The Danish Council for Climate Change, 2020, Section 5.4). More ambitious mitigation targets in line with what proposed here would likely require somewhat higher taxes. Springmann et al. (2018), for example, show that internalizing the social costs of health, which largely coincides with making consumption of meat sustainable (see Willett et al., 2019) would imply optimally increases in taxes on meat that would in turn push prices of red meat up by between $22-34 \%$ and by between $109-185 \%$ for processed meat for a country like Denmark. The success of these taxes in shifting consumption is well known for tobacco smoking and alcohol, and recent evidence is emerging on their effectiveness in curbing the consumption of carbonated drinks, for example in Chile and Oman, where 'sin' taxes to shift buying habits away from these goods were introduced in 2011 and 2017, respectively. Just as it has for cigarettes and alcohol, a tax on high-externality foods would pay a double dividend by simultaneously boosting revenues and lowering consumption (and related social/medical problems). Research shows that, while possibly not immediately effective at curbing undesired consumption - as some 'sin' tax experiments on fat and sugary food, for example in Hungary, indicate- Pigouvian taxes on food may work well in the long run. ${ }^{81}$

\footnotetext{
${ }^{81}$ See Batini and Fontana (forthcoming).
} 


\section{Lessons from past experiments in Denmark with 'sin' taxes on fatty and sugary foods should be internalized by flanking the tax with transfers and adequate structural} reforms. In 2011 Denmark's introduced the world's first "fat" tax but the tax was eliminated only after 15 months. ${ }^{82}$ The reasons for the abolition of the tax are often identified in the many negative side effects hitting businesses as the supply chain was not prepared for switching out of fat as an ingredient or output given the high rate of consumption. Consumers also seemed to have substituted foods going for cheaper food following the price increase, hoarding ahead of the introduction of the tax and importing more by shopping across the border. The effect of the tax on revenues was positive because demand was more rigid than expected. Health effects are debated, although there has been some revisionism of initial critiques, finding that there were positive health effects even if the tax was short lived. ${ }^{83}$ Learning from this experience, a tax on unsustainable/unhealthy food should be accompanied by cuts in taxes on sustainable/healthy food or a structure of feebates calibrated across the food basket depending on environmental and health externalities associated with large categories of food to ensure that consumers' food purchasing power would not be diminished; aggressive climate and nutrition educational and marketing campaigns (also banning aggressive animal-based food marketing); and incentives to retail/restaurants to continue innovate - as Denmark already champions food innovation globally, for example with research conducted at the Nordic Food Lab in Copenhagen. Changes in health services, including more emphasis on lifestyle choices accompanied by fiscal incentives would also help making the tax a success (Batini and Fontana, forthcoming).

The Chilean example lends support to the view that strong marketing, educational and regulatory campaigns can help the success of tax increases on unhealthy food. ${ }^{84}$

\section{Likewise, various options are available to modify the allocation of CAP subsidies in support of more sustainable production. ${ }^{85}$ While the overall envelope and general} guidelines governing CAP subsidies depend on the EU's collective policy decisions, the recently reformed CAP offers considerable greater flexibility in the allocation of subsidies to member countries in the context of both Pillar 1-funded by the European Agricultural

\footnotetext{
${ }^{82}$ The tax was a surcharge on foods that are high in saturated fat. Butter, milk, cheese, pizza, meat, oil and processed food became subject to the tax if they contained more than 2.3 percent saturated fat.

${ }^{83}$ See for example https://www.euractiv.com/section/health-consumers/news/study-fat-tax-made-denmarkhealthier/.

${ }^{84}$ See https://www.nytimes.com/2020/02/11/health/chile-soda-warninglabel.html\#: : :text=The\%20regulations\%20followed $\% 20 \mathrm{a} \% 202014, \% 2 \mathrm{C} \% 20$ sugar $\% 2 \mathrm{C} \% 20$ fat $\% 20$ or $\% 20$ calori es.

${ }^{85}$ As a member of the EU, Danish agricultural production is subject to the EU's Common Agricultural Policy (CAP), and it is thus heavily affected by changes to the CAP. Introduced in 1962, the CAP has undergone several changes since then to reduce the cost (from 71 percent of the EU budget in 1984 to 39 percent in 2013) and to also consider rural development in its aims. The CAP works through a system of agricultural subsidies and price/market support programs and has long exerted a strong influence on agricultural and land change practices in Europe.
} 
Guarantee Fund (EAGF) - and Pillar 2 - that is based on Rural Development Programs (RDPs) co-financed by the European Agricultural Fund for Rural Development (EAFRD) and EU Member States. It follows that a large share of Denmark's CAP entitlements can potentially be gradually redirected to help generate the new pursued market equilibrium. Main areas of flexibility include: (i) transfer of funds between Pillar 1 and 2 or vice versa to shift support in favor of low- or no-externality-generating activities; (ii) targeting to desired commodities commodity-specific payments funded from the national budget in addition to SAPS aid, including through the transitional national aid (TNA) scheme; (iii) leveraging of rules under the CAP's new voluntary coupled support (VCS) to allocate a larger subsidy envelope to desired production (i.e. low-externality crops and breeds) sub-sectors or regions (to better tailor the use of indigenous resources/energy to low-externality crops and breeds). ${ }^{86}$ Further changes to the CAP, for example allowing rewilded lands-like peatlands in Denmark - to receive green subsidies, would be welcome and could accelerate plans, like those suggested by the Danish Council for Climate Change, ${ }^{87}$ to put a halt to peatland drainage aimed at receiving EU subsidies because it would level the financial incentives playing field between arable land and land destined to conservation/carbon sequestration.

In the long run, the shift in national allocation of CAP subsidies should reflect desired equilibrium supply allocations. During the transition to the new production equilibrium, however, a greater-than-proportional allocation may be necessary to help a sufficient number of sustainable farmers enter the market and become profitable.

Tax schemes to internalize public health risks and negative environmental externalities from fur farming and whaling coupled with fiscal incentives in the form of transfers can help them transition into activities that are sustainable. New business models can be developed in both areas creating an equivalent or larger number of jobs with the help of government support schemes during the transition. One promising area in countries with extended coastal areas like Denmark and its territories is restorative ocean farming, based on zero-input 3D farms at sea that grow seaweed, oysters, clams and mussels and have thus the potential to both capture large amounts of carbon, ${ }^{88}$ produce protein suitable at once for people and animal nutrition, foster ecosystem conservation and create millions of jobs ${ }^{89}$

\footnotetext{
${ }^{86}$ See Batini (2019) for similar recommendations for the case of France, another EU country subject to the CAP.

${ }^{87}$ The Danish Council on Climate Change (2020) estimates that halting peatland drainage could cut 1.4 million tons of CO2-eq by 2030.

${ }^{88}$ If adopted globally, this could shave yearly global GHGs by up to 15 percent.

${ }^{89}$ According to the World Bank, farming seaweed in 5\% of U.S. waters, for example, has the potential to create 50 million jobs - the biggest job creator since World War II (World Bank, 2016).
} 
(Batini and Smith, forthcoming). Marine mammal-based ecotourism, especially whalewatching is another form of commercial and non-consumptive wildlife activity (marine tourism globally produces already more revenue than aquaculture and fisheries put together and for many coastal communities, this industry is becoming the most significant economic activity). ${ }^{90}$ On land, activities like conservation and ecosystem restoration can offer jobs replacing employment in environment/health risky activities, in line with many existing proposals for a post-COVID green recovery, and the European Green Deal. Government reforms including training and regulatory changes, in addition to outright financial support and support to credit, can greatly facilitate these transitions.

\section{Summary of Policy Recommendations}

Addressing climate change requires a global effort, and Denmark is a potential lab for other countries on how to put together a comprehensive strategy for implementing a transition to an emission-neutral economy. This paper makes a variety of recommendations for elements of this strategy including:

- Apply a domestic carbon surcharge to emissions covered by the EU ETS with rate equal to the difference between a target emissions price (ramping up predictably over time) and the EU ETS allowance price;

- Set a trajectory of rates for the domestic carbon tax in line with the (combined) price on emissions covered by the EU ETS;

- Embed carbon pricing as part of a broader fiscal reform, involving broad reductions in labor income taxes to boost the economy in a distributionally balanced manner;

- Modify the existing vehicle registration tax system to include (i) a revenue-neutral feebate to promote low-emission vehicles and (ii) removal of registration tax exemptions for EVs to maintain revenue;

- Consider broader application of feebates for the industrial, power generation, electricity consumption, and land-use sectors;

- Push for an exogenously set, and progressively rising, carbon price floor at the EU level to underpin the ETS and increasing the linear reduction factor for the cap;

\footnotetext{
${ }^{90}$ The International Fund for Animal Welfare estimated the value of this business at \$2.1 billion back in 2008 . This eco-business has been increasing exponentially in Europe, Asia, the Caribbean, and South America since then.
} 
- Complement the phase out of ICE vehicles with km-based charging systems (varying by region and time of day) to maintain transportation revenues and efficiently manage road congestion;

- Consider a BCA based on the carbon content of imports, starting with EITE industries;

- Consider implementing proxy pricing schemes using data routinely collected on farmlevel operations to disincentivize unsustainable animal and crop farming and incentivize sustainable food production and carbon sequestration activities. These should be calibrated on the basis of notional targets for reducing large and highemission animals over time like cattle and pigs. Flanking Denmark's bold mitigation strategy in the energy sector with a parallel strategy in the agricultural sector, for example by targeting a halving of Denmark populous livestock by 2030, can help balance better the burden on each sector implying softer trade-offs, more certain outcomes as well as a number of ancillary co-benefits in terms of natural resources, public health (with potentially significant fiscal saving in healthcare spending) and biodiversity.

- Design government support schemes to foster the transition away from intensive animal farming and fishing, including fur farming, and whaling toward sustainable activities on land and at sea, like regenerative agroecology and fisheries, forest, land and coastal conservation, and eco-tourism. Support should extend to training, direct and indirect government credit and regulatory simplification.

- Consider implementing tax schemes to discourage the overconsumption of meat and dairy and increase that of plant-based diets, in line with scientific dietary recommendations. Couple this with education and health reforms structural reforms fostering healthy nutrition and reducing food waste. A joint supply and demand strategy is needed to mitigate GHG emissions in the agriculture, fishery and forestry sector to avoid emissions leakage and validate the new food system equilibrium. 


\section{REFERENCES}

Automobile Commission, 2020. Roads to a Greener Vehicle Taxation. Report prepared for the Danish Ministry of Finance. Copenhagen, Denmark. Available at: https://fm.dk/udgivelser/2020/september/delrapport-1-veje-til-groen-bilbeskatning

Batini, Nicoletta, 2019. "Macroeconomic Gains from Reforming the Agri-Food Sector: The Case of France”. International Monetary Fund WP No. 19/41. (Washington: International Monetary Fund). Available at: https://www.imf.org/en/Publications/WP/Issues/2019/02/26/Macroeconomic-Gains-fromReforming-the-Agri-Food-Sector-The-Case-of-France-46583

— forthcoming. The Economics of Sustainable Food: Smart Policies for Health and the Planet. Island Press and International Monetary Fund, Washington DC.

Batini, Nicoletta and Philippe Pointereau, forthcoming. "Greening Food Supply in Advanced Economies" in The Economics of Sustainable Food: Smart Policies for Health and the Planet, Batini, Nicoletta (ed.). Island Press and International Monetary Fund.

Batini, Nicoletta and Bren Smith, forthcoming. "Regenerative Ocean Farming" in The Economics of Sustainable Food: Smart Policies for Health and the Planet, Batini, Nicoletta (ed.). Island Press and International Monetary Fund.

Bajželj, Bojana, Keith S. Richards, Julian M. Allwood, Pete Smith, John S. Dennis, Elizabeth Curmi \& Christopher A. Gilligan et al., 2014. "Importance of food-demand management for climate mitigation," Nature Climate Change, 4:924-929.

Bloomberg, 2020. The European Carbon Market Rally is far from Over.

Böhringer, Christoph, Edward J. Balistreri, and Thomas F. Rutherford. "The role of border carbon adjustment in unilateral climate policy: Overview of an Energy Modeling Forum study (EMF 29).” Energy Economics 34 (2012): S97-S110.

Branger, Frédéric, and Philippe Quirion, 2014. 'Climate policy and the 'carbon haven' effect." Wiley Interdisciplinary Reviews: Climate Change 5, no. 1: 53-71.

Bunch, David S., David L. Greene, Timothy Lipman, Dr. Elliot Martin and Dr. Susan Shaheen, 2011. Potential Design, Implementation, and Benefits of a Feebate Program for New Passenger Vehicles in California, pp. 59-61, prepared for the State of California Air Resources Board and the California Environmental Protection Agency. 
Calder, Jack, 2015. "Administration of a U.S. Carbon Tax," In Implementing a U.S. Carbon Tax: Challenges and Debates, edited by I. Parry, A. Morris, and R. Williams (New York: Routledge).

CAT, 2020. 2100 Warming Projections. Climate Action Tracker. Available at: https://climateactiontracker.org/global/temperatures.

Chami, Ralph, Thomas Cosimano, Connel Fullenkamp, and Sena Oztosun, 2019. "Nature's Solution to Climate Change: A strategy to protect whales can limit greenhouse gases and global warming," Finance and Development, 56(4), (Washington: International Monetary Fund).

Chami, Ralph, Thomas Cosimano, Connel Fullenkamp, Fabio Berzaghi, Sonia EspanolJimenez, Milton Marcondes and Joe Palazzo, 2020. "On Valuing Nature-Based Solutions to Climate Change: A Framework with Application to Elephant and Whales". ERID Working Paper No. 297.

Clements, Benedict, and David Coady, Stefania Fabrizio, Sanjeev Gupta, Trevor Alleyne, and Carlos Sdralevich, editors, 2013. Energy Subsidy Reform: Lessons and Implications (Washington: International Monetary Fund).

Coady, David, 2006. "Indirect tax and public pricing reforms," in Analyzing the distributional impact of reforms: A practitioner's guide to pension, health, labor markets, public sector downsizing, taxation, decentralization, and macroeconomic modeling (Vol. 2), edited by Aline Coudouel and Stefano Paternostro, World Bank Group, Washington, D.C.

Coady, D., I. Parry, and B. Shang, 2018. "Energy Price Reform: Lessons for Policymakers." Review of Environmental Economics and Policy 12: 197-219.

Dalgaard, Randi L., 2007. The environmental impact of pork production from a life cycle perspective. University of Aarhus and Aalborg University. (Ph.D. thesis).

Dall, Margit and Aaslyng Marchen Hviid, 2020. "Meat quality in the Danish pig population anno 2018," Meat Science, 163:108034.

Danish Agriculture and Food Council, 2019. Annual Statistics for Pigmeat, Beef and Dairy.

Danish Council for Climate Change, 2016. Effektive veje til drivhusgasreduktion i landbruget. Available at: https://klimaraadet.dk/da/analyser/effektive-veje-tildrivhusgasreduktion-i-landbruget 
- 2020. Known Paths and New Tracks to 70 percent Reduction. Available at https://klimaraadet.dk/en/rapporter/known-paths-and-new-tracks-70-cent-reduction

Danish Economic Councils, 2009. Economy and Environment 2009, Available at: https://dors.dk/vismandsrapporter/okonomi-miljo-2009

- 2019. Economy and Environment 2019, Available at:

https://dors.dk/vismandsrapporter/oekonomi-miljoe-2019

EU Fusions Project, 2016. (project contributors: Stenmarck, Asa, Carl Jensen, Tom Quested, Graham Moates). Estimates of European food waste levels. Available at: https://www.eufusions.org/phocadownload/Publications/D3.5\%20recommendations $\% 20$ and $\% 20$ guidelines $\% 20$ food $\% 20$ waste $\% 20$ policy $\% 20$ FINAL.pdf.

Food and Agriculture Organization, 2017. Global Livestock Environmental Assessment Model (GLEAM). Available at: www.fao.org/gleam/en/

Fischer, Carolyn, Richard Morgenstern and Nathan Richardson, 2015. "Carbon Taxes and Energy-Intensive Trade-Exposed Industries: Impacts and Options," In Implementing a U.S. Carbon Tax: Challenges and Debates, edited by I. Parry, A. Morris, and R. Williams. New York: Routledge.

Flachsland, Christian, Michael Pahle, Dallas Burtraw, Ottmar Edenhofer, Milan Elkerbout, Carolyn Fischer, Oliver Tietjen, and Lars Zetterberg, 2018. "Five Myths About a European Union Emissions Trading System Carbon Price Floor." Resources for the Future, Washington, DC.

Goulder, Lawrence H., Dallas Burtraw and Roberton C. Williams, 1999. "The CostEffectiveness of Alternative Instruments for Environmental Protection in a Second-Best Setting.” Journal of Public Economics, Vol. 72, pp. 329-360.

Government of the Netherlands, 2019. Climate Agreement. The Hague. Available at: www.government.nl/documents/reports/2019/06/28/climate-agreement.

Grossi, Giampiero, Pietro Goglio, Andrea Vitali, Adrian G. Williams, 2019. "Livestock and climate change: impact of livestock on climate and mitigation strategies," Animal Frontiers, Volume 9, no. 1:69-76, https://doi.org/10.1093/af/vfy034

Harwatt Helen, William J. Ripple, Abhishek Chaudhary, Matthew G. Betts, Matthew N. Hayek, 2020. "Scientists call for renewed Paris pledges to transform agriculture." Lancet Planet Health, 4, no: 1: e9-e10. 
Hauken, Paul, 2017. Drawdown: The Most Comprehensive Plan Ever Proposed to Reverse Global Warming. Penguin Books.

He, Y., S. E. Trumbore, M. S. Torn, J. W. Harden, L. J. S. Vaughn, S. D. Allison, J. T. Randerson, 2016. "Radiocarbon constraints imply reduced carbon uptake by soils during the 21st century," Science, 353, no. 6306:1419-1424.

Hirst, D., 2018. Carbon Price Floor (CPF) and Price Support Mechanism, Briefing paper 05927, House of Commons Library.

ICAP, 2020. Korea Emissions Trading System. International Carbon Action Partnership.

IEA, 2020. Global Energy Review 2020: The Impacts of the Covid-19 Crisis on Global Energy Demand and CO2 Emissions. International Energy Agency, Paris, France.

— 2019. Energy Prices and Taxes, First Quarter. International Energy Agency, Paris, France.

International Monetary Fund, 2019a. How to Mitigate Climate Change, Fiscal Monitor, Washington, DC.

— 2019b. Fiscal Policies for Paris Climate Strategies-From Principle to Practice, Washington, DC.

_ 2020. The Time is Right! Reforming Fuel Pricing Under Low Oil Prices. Forthcoming.

IPCC, 2006. 2006 IPCC Guidelines for National Greenhouse Gas Inventories, Volume 4, Agriculture, Forestry, and Land Use. Inter-Governmental Panel on Climate Change, Geneva, Switzerland. Available at: https://www.ipcc-nggip.iges.or.jp/public/2006gl/vol4.html.

IPCC, 2018. Global Warming of $1.5^{\circ} \mathrm{C}$. Inter-Governmental Panel on Climate Change, Geneva, Switzerland. Available at: https://www.ipcc.ch/sr15.

IPCC 2019. Climate Change and Land: An IPCC Special Report on Climate Change, Desertification, Land Degradation, Sustainable Land Management, Food Security, and Greenhouse Gas Fluxes in Terrestrial Ecosystems. Inter-Governmental Panel on Climate Change, Geneva, Switzerland. Available at: https:/www.ipcc.ch/srccl-report-download-page. Klimaprogram, 2020, Danish Ministry of Energy, Climate and Utilities. https://kefm.dk/Media/6/4/Klimaprogram_2020.pdf

Kool, A., Blonk, H., Ponsioen, T., Sukkel, W., Vermeer, H., de Vries, J. \& Hoste, 
R. 2009. "Carbon footprints of conventional and organic pork assessment of typical production systems in the Netherlands, Denmark, England and Germany." Gouda, Blonk Milieuadvies/WUR.

Lal, R., 2004. "Soil Carbon Sequestration Impacts on Global Climate Change and Food Security," Science, 304.

Leip, Adrian Franz Weiss, Tom Wassenaar, Ignacio Perez, Thomas Fellmann, Philippe Loudjani, Francesco Tubiello, David Grandgirard, Suvi Monni, Katarzyna Biala, 2010. Evaluation of the livestock sector's contribution to the EU greenhouse gas emissions (GGELS) - final report. European Commission, Joint Research Centre.

Lutz, Steven, and Angela, Martin, 2014. "Fish Carbon: Exploring Marine Vertebrate Carbon Services,” Blue Climate Solutions report. (Washington, DC: The Ocean Foundation).

McKinsey, 2018. Charging ahead: Electric-vehicle infrastructure demand. Available at: www.mckinsey.com/industries/automotive-and-assembly/our-insights/charging-aheadelectric-vehicle-infrastructure-demand

MacLeod, M., Gerber, P., Mottet, A., Tempio, G., Falcucci, A., Opio, C., Vellinga, T., Henderson, B., and Steinfeld, H. (2013). Greenhouse gas emissions from pig and chicken supply chains - a global life cycle assessment. Food and Agriculture Organization of the United Nations. http://www.fao.org/3/i3460e/i3460e.pdf

Mansouri, N. Y., R. Chami, C. M. Duarte, Y. Lele, M. Mathur, M. Abdelrahim Osman, 2020. Policy Brief Nature-Based Solutions To Climate Change: Towards A Blue Carbon Economy Future. G20-T20 Task Force 2, Climate Change and Environment.

Ministry of Climate, Energy and Utilities, 2020. Climate Program 2020, Available at: https://kefm.dk/Media/6/4/Klimaprogram_2020.pdf

Ministry of Transport Building and Housing, 2017. National policy framework for implementation of the AFI Directive.

NCEP, 2019. Denmark's Integrated National Energy and Climate Plan. Danish Ministry of Climate, Energy, and Utilities.

Opio, C., Gerber, P., Mottet, A., Falcucci, A., Tempio, G., MacLeod, M., Vellinga, T., Henderson, B., \& Steinfeld, H., 2013. “Greenhouse gas emissions from ruminant supply chains - a global life cycle assessment." Food and Agriculture Organization of the United Nations. http://www.fao.org/3/i3461e/i3461e.pdf 
Parry, Ian W.H., 2019. "The Rationale for, and Design of, Forest Carbon Feebates." Unpublished manuscript, Washington: International Monetary Fund.

— Ian, 2004. “Are Emissions Permits Regressive?” Journal of Environmental Economics and Management 47: 364-387.

Parry, Ian and Roberton Williams, 2012. "Moving US Climate Policy Forward: Are Carbon Tax Shifts the Only Good Alternative?" In Robert Hahn and Alistair Ulph (eds.), Climate Change and Common Sense: Essays in Honor of Tom Schelling, Oxford University Press, 173-202.

Parry, Ian, Dirk Heine, Shanjun Li, and Eliza Lis, 2014. Getting Energy Prices Right: From Principle to Practice. IMF, Washington DC.

Pershing, Andrew J., Line B. Christensen, Nicholas R. Record, Graham D. Sherwood, Peter B. Stetson, 2010. "The Impact of Whaling on the Ocean Carbon Cycle: Why Bigger Was Better," PLOS One, https://doi.org/10.1371/journal.pone.0012444.

Petersen, S. O, 2018. "Greenhouse gas emissions from liquid dairy manure: Prediction and mitigation," Journal of Dairy Science, 101 (7), 6642-6654.

Project Drawdown Team, 2020. The Drawdown Review.

Rockström, Johan, Owen Gaffney, Joeri Rogelj, Malte Meinshausen, Nebojsa Nakicenovic, Hans Joachim Schellnhuber et al., 2017. “A Roadmap for Rapid Decarbonization,” Science, Vol. 355, Issue 6331, 1269-1271.

Roman, J., J. Estes, L. Morissette, C. Smith, D. Costa, J. McCarthy, J. B. Nation, S. Nicol, A. Pershing, and V. Smetacek. 2014. "Whales as Marine Ecosystem Engineers," Frontiers in Ecology and the Environment, 12, no. 2: 377-85.

Pauer, Stephan, 2018. “Including Electricity Imports in California's Cap-and-Trade Program: A Case Study of a Border Carbon Adjustment in Practice." The Electricity Journal 31: 39-45.

Safina, Carl, 2020. Becoming Wild: How Animal Cultures Raise Families, Create Beauty, and Achieve Peace. (New York, NY: Henri Holt and Co.).

Sato, Misato, 2014. "Embodied Carbon in Trade: A Survey of the Empirical Literature," Journal of Economic Surveys, 28, no.5: 831-861.

Simon, David Robinson, 2013. Meatonomics. Conari Press. 
Sijm, J. and others, 2012. "The impact of power market structure on the pass-through of CO2 emissions trading costs to electricity prices - A theoretical approach". Energy Economics, Elsevier, 34: 1143-1152.

Solagro, 2016. Afterres2050 (version 2016).

Springmann, Marco, Daniel Mason-D’Croz, Sherman Robinson, Keith Wiebe, H. Charles J. Godfray, Mike Rayner, Peter Scarborough, 2018. "Health-motivated taxes on red and processed meat: A modelling study on optimal tax levels and associated health impacts," PLOS ONE, https://doi.org/10.1371/journal.pone.0204139.

Tsyvinski, A., and Werquin, N. 2019. "Generalized Compensation Principle," Toulouse School of Economics Working Paper No. 19-1051.

Vallgårda, S., Holm, L. and Jensen, J., 2015. "The Danish tax on saturated fat: Why it did not survive," European Journal of Clinical Nutrition, 69, 223-226.

Verdolini, E., Vona, F., and D. Popp, 2018. "Bridging the Gap: Do Fast Reacting Fossil Technologies Facilitate Renewable Energy Diffusion?” Energy Policy 116: 242-256.

Van de Kamp, M. E., Seves, S. M., and Temme, E. H., 2018. "Reducing GHG emissions while improving diet quality: exploring the potential of reduced meat, cheese and alcoholic and soft drinks consumption at specific moments during the day," BMC Public Health, 18, no.1:264.

Wallace, John R., Goor Sasson, Philip C. Garnsworthy, Ilma Tapio, Emma Gregson, Paolo Bani, Pekka Huhtanen, Ali R. Bayat, Francesco Strozzi, Filippo Biscarini, et al., 2019. "A heritable subset of the core rumen microbiome dictates dairy cow productivity and emissions." Science Advances, 5, no. 7: eaav839.1

Willett, Walter, Johan Rockström, Brent Loken, Marco Springmann, et al., 2019. "Food in the Anthropocene: the EAT-Lancet Commission on healthy diets from sustainable food systems," EAT-Lancet EAT-Lancet Commission on healthy diets from sustainable food systems.

Wier, Mette, Katja Birr-Pedersen, Henrik Klinge Jacobsen, and Jacob Klok, 2005. "Are CO2 taxes regressive? Evidence from the Danish experience," Ecological Economics, 52(2), 239251.

Wingender, Philippe and Florian Misch, forthcoming. "Emission Spillovers from Carbon Price Increases: New Evidence and Policy Questions,” IMF Working Paper. 
World Health Organization, 2020. Healthy Diet, Available at: https://www.who.int/newsroom/fact-sheets/detail/healthy-diet 


\section{ANNEX I. HouSEHOLd INCIDENCE OF A CARbON TAX}

The incidence of carbon tax changes depends on changes in: i) energy prices, ii) prices for other goods and services, and iii) wages. The derivation below follows the approach proposed by Coady (2006).

\section{Production and pass through to non-energy goods}

Assume profits of a representative firm are given by

$$
\Pi_{j}=p_{j} f\left(A_{j}, E_{j}, L_{j}\right)-q A_{j}-r E_{j}-w_{j} L_{j}
$$

with $p_{j}$ the supplier price of good $j, q$ a $1 \times n$ row vector of user prices for intermediate inputs and $A_{j}$ a $n \times 1$ column vector of quantities, $r$ and $E_{j}$ the price and quantity of energy, and with labor costs $w_{j} L_{j}$. The element $A_{i j}$ denotes the quantify of input $i$ needed to produce output $y_{j}$. We assume Leontief production $Y_{j}=f\left(A_{j}, E_{j}, L_{j}\right)$ so that input shares are fixed. Producer and user prices are related by $q=p+t$, with $t$ general sales and excise taxes, tariffs and subsidies.

A carbon tax $\tau$ directly affects the user price of energy $r$ and indirectly the prices of other domestic inputs $q$

$$
\frac{\partial \pi_{j}}{\partial \tau}=\frac{\partial p_{j}}{\partial \tau}-\frac{\partial q}{\partial \tau} a_{j}-\frac{\partial r}{\partial \tau} e_{j}-\frac{\partial w_{j}}{\partial \tau} l_{j}
$$

with $x_{j}=X_{j} Y_{j}^{-1}$. For domestic suppliers, we further assume that:

- Higher input costs are fully passed on through higher producer prices $p_{j}^{d}$

- Profits are constant through a no-arbitrage condition

- User prices of imported goods are not affected.

This implies

$$
\frac{\partial p_{j}^{d}}{\partial \tau}=\frac{\partial q^{d}}{\partial \tau} \alpha a_{j}+\frac{\partial r}{\partial \tau} e_{j}
$$

with $\alpha$ a diagonal matrix that denotes the share of goods that are produced domestically. When other taxes remain constant, changes in producer prices of non-energy goods are equal to changes in user prices. Re-expressing price changes in Eq. (3) in percentage terms and concatenating across goods yields 


$$
\frac{\partial \dot{p}^{d}}{\partial \tau}=\frac{\partial \dot{q}^{d}}{\partial \tau}=\frac{\partial \dot{q}^{d}}{\partial \tau} \alpha \Lambda+\frac{\partial \dot{r}}{\partial \tau} \Sigma,
$$

with $\partial \dot{x} \equiv \partial x / x$ the percentage price changes, the matrix $\Lambda$ an input-output coefficient matrix of size $n \times n$ and $1 \times n$ row vector of energy intensity $\Sigma=\left[\frac{r E_{1}}{p_{1}^{d} Y_{1}}, \frac{r E_{2}}{p_{2}^{d} Y_{2}}, \ldots, \frac{r E_{n}}{p_{n}^{d} Y_{n}}\right]$.

Rearranging, we can solve for changes in user prices

$$
\frac{\partial \dot{q}^{d}}{\partial \tau}=\frac{\partial \dot{r}}{\partial \tau} \Sigma K
$$

with Leontief inverse matrix $K=(I-\alpha \Lambda)^{-1}$.

In the case of exporters, we further assume

- Perfect substitutability with foreign goods so that higher input costs are instead passed back to wages

- No labor reallocation between exporters and domestic suppliers.

From Eq. (2),

$$
\frac{\partial w_{j}^{*}}{\partial \tau} l_{j}=-\frac{\partial q^{d}}{\partial \tau} \alpha a_{j}-\frac{\partial r}{\partial \tau} e_{j}
$$

which can be re-expressed as

$$
\frac{\partial \dot{w}_{j}^{*}}{\partial \tau}=-\frac{\partial \dot{r}}{\partial \tau} \Sigma(I+K \alpha \Lambda) \lambda^{-1}
$$

where the elements of the diagonal matrix $\lambda$ are equal to the labor intensity of production $w_{j} L_{j} / p_{j}^{d} Y_{j}$.

\section{Household incidence}

The impact of a carbon tax on household welfare is then given by

\footnotetext{
${ }^{1}$ A standard input-output matrix would also include energy inputs. The notation used here effectively precludes second-round effects on energy price themselves. Both approaches are equivalent however when the carbon policy targets the total energy price change.
} 


$$
\frac{\partial U_{j}}{\partial \tau}=\sum_{i} \omega_{i j} \frac{\partial \dot{q}_{i j}}{\partial \tau}-\frac{\partial \dot{w}_{j}}{\partial \tau}
$$

where the percentage changes in user prices are weighted by their final consumption budget shares $\omega_{i}$. As mentioned above, we assume only the price of energy and domestically produced non-energy goods are affected by the carbon tax, while only wages paid by exporters are reduced. The final incidence in partial equilibrium on households is given by

$$
\frac{\partial U_{j}}{\partial \tau}=\sum_{i} \omega_{i j} \tilde{\alpha}_{i} \frac{\partial \dot{q}_{i j}^{d}}{\partial \tau}-\beta_{i} \frac{\partial \dot{w}_{j}^{*}}{\partial \tau}
$$

where $\tilde{\alpha}_{i}$ is the share of final consumption of good $i$ that is produced domestically and $\beta_{i}$ the export share of good $i$.

For the empirical implementation, we use energy price changes resulting from a carbon tax from the model developed by Parry and others (2014). The price changes of other domestic supplies is calculated from an input-output table for Denmark using Eq. (2) and matched to consumption tables by income quintiles from Eurostat. Wage changes for exporters by sector are calculated from Eq. (3) and matched to household survey data to calculate changes in wages throughout the income distribution. 


\section{ANNEX II. BuRden OF CARbon Mitigation Policies on EITE InduSTRIES}

The burden - or increase in private production costs-for EITEs from carbon mitigation policies is depicted graphically in the Figure. Here the upper, middle, and lower curves are respectively the marginal cost of reducing emissions through reducing domestic industry output, reducing the emissions intensity of output and the envelope of these two curves. A carbon pricing policy reduces emissions by $\Delta \mathrm{E}^{\text {tot }}$, with $\Delta \mathrm{E}^{\text {int }}$ and $\Delta \mathrm{E}^{\text {out }}$ coming from reduced

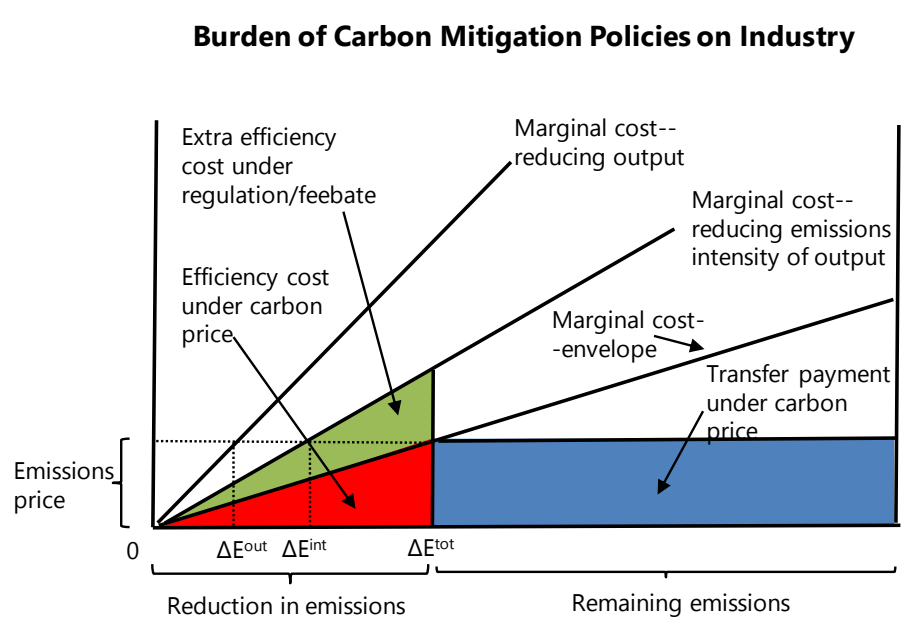
emissions intensity and reduced output respectively. The burden of the carbon price on EITE industries has two components. One is the second-order efficiency cost of the behavioral responses (the red triangle in the Figure) reflecting the resource cost of adopting cleaner (but costlier) production methods. The other is the first-order transfer payment (e.g., tax payment to the government) reflecting the charge on remaining emissions (the blue rectangle). Free allowance allocation offsets the transfer payment component of the burden, though this is a smaller share of the total burden at higher levels of emissions reduction.

Alternative mitigation instruments to carbon pricing are less efficient but may impose a much smaller burden on EITE industries. A feebate applied to an EITE industry reduces emissions intensity but (to an approximation) has no impact on output as, unlike a carbon price, it does not charge for remaining emissions. The burden of the feebate - assuming the industry emissions reduction is the same as under the carbon price-includes a higher efficiency cost (the extra green triangle in the Figure) but there is no transfer payment. The efficiency cost of the feebate (again from simple geometry) is equivalent to that under carbon pricing (the red triangle) times $\Delta \mathrm{E}^{\text {tot }} / \Delta \mathrm{E}^{\text {int }}$. But the overall burden is generally lower under the feebate, especially for relatively low abatement levels, as there is no transfer payment under these policies. For example, if $\Delta \mathrm{E}^{\mathrm{tot}} / \Delta \mathrm{E}^{\mathrm{int}}=1.5$ (i.e., two-thirds of the emissions reduction under the carbon price comes from reduced emissions intensity) the burden of the feebate is 21,50 , and 90 percent of that of carbon pricing for emissions reductions of 25,50 , and 75 percent respectively. 